\title{
CREENCIAS Y SOLUCIONES: GALILEGO Y EL PROBLEMA DE LA ACELERACIÓN *
}

\author{
Juan Vicente MAYORAL DE LUCAS \\ UNED
}

\section{Introducción}

En el De motu dialogus, Galileo realizaba una interpretación ${ }^{1}$ matemática del movimiento local, que comenzaba por una reconstrucción cuantitativa de corte arquimediano de las bases físicas del movimiento. A través de esa interpretación, Galileo intentaba ofrecer un esquema matemático de un fenómeno físico local, tratando mediante argumentos cuantitativos y relacionales una cuestión normalmente englobada en el problema metafísico del cambio ${ }^{2}$. Este intento no es de naturaleza revisionista hacia el esquema conjunto de creencias

- El prof. Solis demostró una gran paciencia al leer y corregir los abstrusos borradores de este artículo, y apoyó desde un principio el proyecto. Por todo ello le estoy sumamente agradecido. Sobre el resultado final asumo, no obstante, toda la responsabilidad.

I Interpretar no conlleva desprenderse de aquello que se interpreta. La interpretación conlleva trasladar términos desde una red conceptual a otra (cada red se compone de esos términos, de conceptos y de los modos de relación entre ellos). El proceso puede tener, por lo menos, dos fines distinguibles (aunque sólo de una manera algo artificial): uno de «comprensión» de lo interpretado en lo que puede representarse como un intento de "recreación"; otro *creativon, en el que lo que importa es el valor y coherencia de la interpretación como representación adecuada de nuestras intenciones. La interpretación galileana se asemeja mucho más al segundo tipo que al primero, aunque esto traería consigo una discusión detallada acerca de lo borroso de tal distinción. Discusión que no tiene sentido iniciar aquil.

2 La cuantificación de conceptos relacionados con el movimiento local aparece, no obstante, como muestra Simplicio, con Arquitas (contemporáneo de Platón) y, pasando por Simplicio, llega a Filopón. Esta cuantificación proviene, como indica SAMBURSKY, de una tradición más cuantitativista de corte platónico. Cf. SAMBURSKY, 1990, págs. 96-101. No obstante, la reducción a un tratamiento arquimediano de Galileo de los problemas físico-metafísicos de Aristóteles es -aunque en un ámbito reducido del movimiento local-mucho más general. 
aristotélico, sino sólo en lo referente al papel de las matemáticas en la investigación física, un papel no reconocido en la ciencia aristotélica. Así, el objetivo era presentar un nuevo modo metodológicamente renovador de ver viejos hechos, cuyo esquema ontológico continúa siendo aristotélico (Galileo continuaba siéndolo).

Como veremos en este artículo, existen elementos de contradicción en el esquema aristotélico de fenómenos como el de calda libre, si éste es interpretado matemáticamente desde el esquema cuantitativo de Galileo. Esos elementos de contradicción giran entorno a la concepción de aceleración accidental del movimiento de caída libre y, lo que es más importante, sólo se pondrán de manifiesto a través del mencionado proceso interpretativo.

La interpretación galileana del De motu constituye, precisamente por tales elementos de contradicción, un resultado inconcluyente tanto para un aristotélico como para un matemático arquimediano. En las siguientes secciones de este trabajo apreciaremos cómo esas fuertes contradicciones internas muestran una tensión entre el sustrato ontológico aristotélico empleado y la nueva metodología matemática. Pero tras tales resultados no observamos un abandono del nuevo enfoque metodológico (que ya había dado demasiados problemas y que no correspondía a un enfoque aristotélico tradicional), sino una perseverancia en el mismo. El De motu no fue jamas publicado, pero al primer proceso de interpretación le siguió una radicalización del punto de vista matemático que pasaba por desechar la participación de elementos ontológicos aristotélicos, tanto en la investigación como en el proceso argumentativo acerca de los problemas físicos, como el del citado movimiento local. Esta radicalización incluye un planteamiento metodológico desarrollado y pulido por el propio Galileo sobre el que hablaremos en profundidad.

El proceso es tremendamente interesante, por cuanto que en él se aprecia el germen del cambio galileano en el estudio del movimiento, una de las aportaciones fundamentales de Galileo a la Revolución Científica. En este artículo presentaré un relato histórico de todo ello. Comenzaré con una descripción analítica de en qué consiste ese proceso interpretativo presentado en el $D e$ motu; continuaré aludiendo a los problemas surgidos de tal programa mixto; y describiré después el constructo metodológico empleado a partir del momento en que, abandonando dicho programa, Galileo radicaliza su nueva postura. Un instante en que, como reza el título del artículo, Galileo elige las soluciones 
(matemáticas, locales) en detrimento de las creencias (ontológicas) como objetivo prioritario (y terreno) de su investigación.

En las páginas siguientes presentaré además un tratamiento explícito de en qué consiste el proceso de opción por las soluciones en detrimento de las creencias. Describiré qué proceso sigue Galileo hasta alcanzar ese plano de trabajo e investigación. Mostraré que el problema de la aceleración en el movimiento, que es tratado mediante el nuevo enfoque metodológico (de cuyo desarrollo galileano hablaré) y sobre ese "plano de las soluciones", surge después de la interpretación matemática. Ese problema toma la forma de una inconsistencia teórica en el caso de mantener tal metodología con un escenario ontológico aristotélico. Por último, presentaré como condición de posibilidad para esta transformación la educación de Galileo en un conjunto de tradiciones matemáticas que se ocupan de los problemas de la mecánica empleando la geometría y excluyendo de su investigación la discusión de las creencias ontológicas. Galileo conoce estas tradiciones que, de Arquímedes a Tartaglia, llegan a (o se desarrollan en) la Italia del siglo XVI y cubren el espectro intelectual junto a las más aristotélicas (y junto a otras que no entran en tan estrecha clasificación, de las que hablaremos), también conocidas por nuestro filósofo-matemático.

Pero en todo ello hay un par de decisiones que requieren explicacion: ¿qué impele a Galileo a la primera interpretacion y a la posterior radicalización (su opción por las soluciones)? $\mathrm{O}$, dicho de otro modo, ¿Qué peso psicológico es lo suficientemente fuerte como para obrar dos veces en contra de un sistema de creencias que define tanto lo que es el mundo como cómo ha de ser estudiado?; ¿Cual es el origen de ese peso psicológico (qué raices tiene)? Estas cuestiones, no respondidas en las próximas páginas, conducen a una línea de investigación que surge a raíz de lo aquil descrito: del desconocimiento de los motivos explícitos que indujeron a Galileo a tomar sendas decisiones. En función de los datos habidos y de la relativa confusión en que está sumergido el conocimiento histórico del pensamiento privado de Galileo, poco se puede decir acerca de los motivos que le condujeron a dar los pasos transformadores de los que aquí vamos a hablar. Este estudio tiene un límite forzado en ese punto $y$, dadas estas condiciones, lo que presentamos aquil puede tomarse como un (relativamente breve, incompleto y esquemático) kestado de la cuestiónm. El enfoque causal comienza más allá de este trabajo, que debe ser tomado, por tanto, como punto de partida más que como cuenta final de resultados 
Las creencias científicas de Galileo y la filosofía natural de Aristóteles ${ }^{3}$

En este apartado vamos a comenzar a recorrer el espacio atravesado por Galileo desde sus creencias basicamente aristotélicas. En la primera subsección expondré de qué manera éstas condicionan los primeros estudios del movimiento. Con ello tendremos una ilustración factual aproximada - pero suficiente para el objetivo de este trabajo- acerca de en qué consiste la creencia. En esta subsección podremos apreciar también de qué trata la interpretación matemática que inaugura la búsqueda galileana de las soluciones - por la vía de raíz arquimediana - a los problemas del movimiento. Tras la interpretación mixta del De motu, Galileo no volvió al terreno aristotélico sobre el que se desarrollaban soluciones filosófica y metafísicamente ortodoxas a los problemas físicos ${ }^{4}$. A partir de ahí la fuente aristotélica de las creencias se convierte en una tradición científica más; una carta en una pequeña baraja cuyos naipes extrae Galileo de cara a la búsqueda de soluciones. En el segundo subapartado estudiaremos con cierto detalle las tradiciones que componen las opciones posibles de Galileo: el resto de los naipes de esa baraja y su papel en el juego de la ciencia y la filosofía de la época.

Como apreciaremos en el siguiente apartado, Galileo no realizará su elección al azar, sino en función de un plan de reforma metodológica (que inclúa criterios alternativos de validez de resultados), con el objetivo de resolver cuanto las soluciones por la vía aristotélica dejan irresuelto. Esa elección de cartas conduce a la aceptación de la aceleración como algo sustancial al movimiento, no accidental; y, a la larga, lleva a un cambio en las creencias, hacia un sistema que, frecuentemente, se ha caracterizado como inaugurado por Galileo -conforme a la línea que aquí veremos nacer- y finalmente perfilado por la ciencia de Newton. Podriamos hablar largamente sobre esto último que, creo, no

3 Véase la Conclusión final, en referencia al por qué de este título.

4 Las soluciones «filosóficamente ortodoxas", que pueden verse en otros textos de Galileo de una fase contemporánea a la redacción del De motu (WALLACE, 1977), implican un modo de argumentación basado en la demostración según el canon lógico aristotélico de los enunciados acerca de una cuestión dada. Galileo buscaria una vía geométrica u otra «filosófican en función de la cuestión tratada - por lo menos en estas fechas-. Sobre la diferencia entre lo que constituye una demostración filosofica según los Analiticos de ARISTOTELES y lo que conlleva una demostración geométrica según los Elementos de Euclides, cf. VEGA, 1986, págs. 23-24 y LLOYD, 1996, págs. 49-58. 
está libre de discusión, pero éste no es el lugar adecuado. Baste con este brevísimo apunte y su comentario y continuemos en nuestro empeño.

\section{Las creencias aristotélicas y la interpretación galileana del movimiento local.}

En el De motu dialogus (Diálogo sobre el movimiento, Drake \& Drabkin, 1969, págs. 331-377), que forma parte de un grupo de escritos recopilados por Antonio Favaro como De motu (y conocidos como De motu antiquiora ${ }^{5}$ ), Galileo escribe una serie de "proposiciones" (incluso podriamos llamarlas "teoremas") inmersos en el diálogo, que pretenden corregir los conceptos de "pesado" y «ligero» definidos por Aristóteles según un criterio de tendencias absolutas de raíz ontológica ${ }^{6}$. Tras la corrección, que aquí hemos dado en llamar

5 Stillman Drake ha puesto de manifiesto, a través de un examen minucioso de los manuscritos y de las pistas que muestran mediante pruebas de marcado el origen de los folios que este grupo no es ni mucho menos un grupo homogéneo. Según el esquema final que presenta Drake (cf. DRAKE, 1986, págs. 429-440; en la pág. 440 hay un esquema ilustrativo), los tratados sobre filosofia natural aristotélica que forman los Juvenilia (Opere, I, págs. 7-177) y los textos del De motu (Opere, I, págs. 251-419) se compusieron intercaladamente y, por ello mismo, se ven sometidos, algunos de ellos a ciertas transformaciones notables originadas en los mismos cambios que se producen en estos afios en el pensamiento de Galileo. Todos ellos se componen en un periodo de seis o siete años, y al tiempo se genera todo un cuerpo de textos relacionados sólo aproximadamente con los asuntos de uno u otro grupo (como La bilancetta, los Discursos sobre el Inferno de Dante, la Demostración en la ciencia y otros). Considero que la reconstrucción de Drake es muy valiosa, pues aporta gran cantidad de datos. Sólo por eso parece dotar de mayor confianza que la de Wallace (en WALLACE, 1977, págs. v-vi, 21-24 y 258-259, en el comentario de la parte de la cuestión anotada como D8 por el propio Wallace), que se apoya en una reconstrucción basada en las "probables" lecturas de Galileo de (o de asistencias a) conferencias de profesores jesuitas del Collegio Romano, dado el parecido del trabajo galileano en estos tratados de los Juvenilia y las fechas coincidentes de aquellas conferencias. Por otro lado Drake realiza frecuentes presunciones sobre el origen de los folios de trabajo de Galileo que dan pie a su propia reconstrucción, por lo que tampoco se salva de la duda.

6 Realmente Aristóteles define sólo el fuego y la tierra como los elementos respectivamente ligero y pesado de manera absoluta, mientras que el aire y el agua lo son (cambién respectivamente) sólo de forma relativa. (ARISTÓTELES, De caelo, IV; ed. ingl. de Jonathan Barnes en BARNES, 1984, págs. 502-511.) La ligereza o pesantez de los cuerpos depende de la preponderancia de unos elementos u otros en ellos, con lo que parece dificil sefialar que en Aristóteles pueda haber una caracterización absoluta de los cuerpos según la dicotomía pesado/ligero. Pero lo que deseo hacer ver en cambio es que si hay una tendencia absoluta en la ontología de Aristóteles a uir hacia arriban que es equivalente a otra de eir hacia abajow. Esas tendencias son absolutas porque lo absolutamente ligero y lo absolutamente pesado (que sí es definible en Aristóteles) han de adquirir su 
interpretación, tales conceptos se configuran como los útiles adecuados a un estudio matemático y dinámico del movimiento. Pero, ¿en qué consiste tal interpretación?

En la interpretación galileana el movimiento hacia abajo de un cuerpo sólido no se produce por la tendencia general de cualquier cuerpo "pesado" a dirigirse de forma obligatoria y absoluta hacia el centro del universo en oposición exacta a la tendencia de los cuerpos ligeros a ir hacia arriba, como ocurría en la física aristotélica. La única tendencia natural considerada es la del propio peso del cuerpo hacia el centro del universo. Así, el hecho de que lo "pesado" se sitúe por debajo de lo "ligero" sigue siendo cierto (luego comentaremos algo a este respecto). Ahora bien, a partir de esta interpretación galileana se plantean las bases para el estudio matemático del movimiento.

En efecto: el estudio se plantea en un entorno exclusivamente locah donde algunas de las previas consideraciones ontológicas (como las tendencias opuestas absolutas "hacia arriba" y "hacia abajo" de Aristóteles; véase Barnes, 1984, págs. 502-511) implican un comportamiento de los cuerpos en caída que posibilita a Galileo el planteamiento de una interpretación de tipo geométrico (aunque con consideraciones fisicas ${ }^{7}$ ). Según el planteamiento de Galileo, para decir que algo es "pesado" o "ligero" en este ámbito local podemos establecer una comparativa entre los cuerpos cuyo peso excede a otros, o es excedido por el de otros. Para ello comenzamos negando la participación de dos tendencias absolutas contrapuestas, cuya acción desde el interior de los cuerpos era la causa de la pesantez o ligereza de los mismos, con lo que después sólo cabe realizar caracterizaciones en función de una comparación cuantitativa; una relativización del peso y la ligereza como atributo de los cuerpos en unas condiciones comparativas dadas ${ }^{8}$. Desde ese punto de vista alternativo se puede describir cuantitativamente un

condición del ser - han de llegar a ser lo que son: la ligereza y pesantez absolutas- al llevar a efecto lo que tales tendencias prescriben, alcanzando el lugar que les es propio (De caelo, IV, 3; BARNES, 1984, págs. 506-507). Más tarde, por las proporciones de esas tendencias introducidas en cada cuerpo a través de su composición elemental, encontramos la ligereza o pesantez de cada cuerpo, que no es nunca absoluta.

7 Consideraciones que, al implicar creencias aristotélicas (como veremos en esta subsección), conducen a contradicciones en el texto que aquí tratamos. De ello hablaremos en la sección siguiente.

8 En relación a los conceptos de pesantez y ligereza, Aristóteles dice haber roto por completo con una serie de tradiciones que él mismo categoriza de urelativistas», frente a la suya que es capaz de dar definiciones absolutas de lo pesado y de lo ligero (ARISTOTELES, De caelo, IV, 1-2; 
mecanismo causal (físico) del movimiento local. De aquella primera diferenciación cualitativa de las cosas de la física aristotélica pasamos a una cuantitativa. Lo "ligero" no se opone cualitativamente a lo "pesado", sino cuantitativamente. lo "ligero" es simplemente "menos pesado» que lo "pesado". De este modo la ordenación del universo viene dado por relaciones entre sustancias cualitativamente iguales - lo cual "neutraliza" los condicionamientos ontológicos- cuya situación en el espacio es una función de una relación cuantitativa entre unas y otras 9 . Por así decirlo, mientras que en Aristóteles la explicación del movimiento implicaba un relato descriptivo que debía regresar hasta las mismas bases ontológicas, en Galileo esa relación de dependencia ontológica pasa a un segundo plano, prevaleciendo en su lugar el tratamiento de problemas físicos mediante el estudio de la relación cuantitativa entre las magnitudes participantes, como causa de los fenómenos del movimiento.

Esta es la fundamentación de la interpretación galileana de las causas del movimiento local en el De motu, básica para un posterior tratamiento matemático del mismo grupo de fenómenos. Como vemos hay un empleo de términos que aluden a las mismas cuestiones observables que antes (o muy similares). Pero ni lo que esos términos significan, ni las relaciones que se establecen entre ellos, son exactamente identificables con los conceptos y relaciones que conllevaba el esquema creencial anterior, el aristotélico.

Con todo, el proceso de "relativización" de la ordenación de sustancias en el universo que Galileo muestra en esas páginas (Drake \& Drabkin, 1969, págs. 338-344) no implica que las creencias cientificas en que Galileo se asienta dejen de ser aristotelicas. Como antes mencionamos ( $\mathrm{y}$ dije que volveríamos sobre ello), el hecho de que lo pesado se sitúe siempre por debajo de lo ligero no varía. En el universo aristotélico en que, en estos comienzos, se dibuja la física galileana, esto presupone la tendencia de los cuerpos hacia el centro del

BARNES, 1984, págs. 502-506). Galileo fue el «recuperador" de un punto de vista relativista, pero con características propias: como menciona SAMBURSKY, (1990, págs. 11-15), Galileo es, junto a Newton, el artífice de la unión de un estudio teórico acerca de la configuración física del mundo con los métodos de resolución técnicos (matemáticos y experimentales) disponibles. Un par de grupos de actividad científica y filosofica que, desde la Antigüedad, hablan venido trabajando en paralelo, pero pocas veces con tal nivel de interacción. En esa virtud se encuentra el origen de tal urecuperación» (que es más bien una definición desde cero) del punto de vista relativista.

9 Sobre lo dicho en este párrafo y lo que sigue, cf. Solfs, 1983, págs. 73-76. 
mismo. La posterior interpretación implica que los cuantitativamente más pesados se sitúan bajo los menos pesados, pero esto no anula la citada ordenación, una auténtica y vigente creencia aristotélica, dentro de un universo también aristotélico. Para esta creencia, Galileo ni siquiera presenta una razón lógica en el texto.

Alessandro: (...) Permítanos, entonces, asumir primero que ha sido acordado por la naturaleza que los cuerpos más pesados permanezcan en reposo bajo los más ligeros. Y está totalmente claro a los sentidos que éste es es el caso.

Domenico: Por supuesto, captamos mediante nuestros sentidos que lo que asume es perfectamente cierto. Pero me gustaria comprender por qué razón la naturaleza ha mantenido esta ordenación más que la opuesta. (Drake \& Drabkin, 1969, págs. 338-339) ${ }^{10}$.

La respuesta que compone Alessandro a ese requerimiento es plenamente inconcluyente. Galileo no alcanza a dar una razón de esa disposición fuera de la propia ordenación como base. Sólo presenta algún caso en apoyo ${ }^{11}$, pero,

10 Traducción propia desde la versión inglesa.

11 Verdaderamente, GALILEO lo admite, no hay una forma de demostrar esta proposición (o no la hay desde el punto de vista de Galileo): «Dar la razón para esta disposición no puede contribuir en nada útil para nuestro propósito, dado que está claro que aquéllos son los hechos. Y sería, sin duda, muy dificil dar la causa precisa. Verdaderamente no sería capaz de dar ninguna otra excepte que aquell as cosas habian de ser dispuestas en alguna disposición. y le ha complacide a la nacuraleza disponerlas de esta maneram. (DRAKE \& DRABKIN, 1969, pág. 339. Subrayado mio). Apunta Drabkin en nota algo de valor sefialado por Galileo en nota marginal (Opere, I, 374): «Et haec est ratio Aristotelis, 8 Phys t. 32.n, 'y esta es la razón de Aristóteles', tras lo cual cita (aclara Drabkin) el pasaje 255b. 13-17 de la Fisica de Aristóteles. (CF. DRAKE \& DrABKIN, 1969, pág. 339, nota 12.) Lo que deseo aclarar con esa nota marginal y el subrayado es que a Galileo no le interesa discutir las bases de la filosofia natural de Aristoteles (i. e. sus propias creencias cientificas), sino presentar un modelo alternativo restringido a los problemas del movimiento local, que si son tratables de la forma en que lo hará (y que aún no ataca a tales bases). De hecho, como afirma en la primera porción subrayada, una discusión sobre tales asuntos tiene muy poco valor en este momento y con este fin. Pero Domenico le pide que de una razón para esa disposición natural, un motivo que le convenza de que esa disposición es la mejor. Y Alessandro da, como prueba posible un argumento basado en la propia disposición como apoyo: los cuerpos más pesados son aquellos que contienen más materia en un menor espacio. (El peso "en especien, que, por oposición al upeso absoluton de corte aristotélico, distingue el peso y la densidad. Galileo realiza eata distinción obligado por su relativización y por la consiguiente eliminación de la sligereza absolutan. Debo agradecer al prof. Souls un fértil comentario a este respecto.) Los espacios del centro del universo esférico son estrechos y, por tanto, los cuerpos más 
como señala Domenico a continuación, "ese argumento no ha de ser considerado una razón concluyente para esta disposición de los elementos." (Drake \& Drabkin, 1969, ibid.) Galileo es muy consciente, en esa frase de su propio interlocutor (y lo que continúa), de que tal proposición, premisa del resto de razonamientos del De motu, ha de ser aceptada como auto-evidente. No creo que Galileo dejara adrede una señal de debilidad en el texto, en la forma de un postulado que para él mismo fuera dudoso. Y tampoco creo que tal aceptación plena de la ordenación nos permita juzgarla como postulado de partida, sino como premisa basada en la "ordenación de sentido común» del universo. Ese es el papel de las creencias científicas, en este caso aristotélicas: la generación de unas condiciones de sentido comuin.

Pese a la crítica a la física aristotélica y a su enfoque metodológico que ya entraña el De motu dialogus, Galileo sigue siendo, por tanto, plenamente aristotélico en sus creencias científicas. El texto de este diálogo implica "modificaciones" en una física de Aristóteles que ya parece necesariamente revisable. Pero ciertas "premisas" básicas de todo razonamiento físico están tan sumamente arraigadas y ocultas entre el resto de creencias científicas que parece anti-intuitivo ponerlas en duda (aunque sean aristotélicas).

A continuación de esa primera fase del diálogo (Drake \& Drabkin, 1969, págs. 331-338) comienza otra en la que se recaracterizan las causas del movimiento de los cuerpos en caída, es decir, del movimiento natural de todo cuerpo. Ahora todo estudio del movimiento local parte de la premisa de que no es necesario aludir a distinciones cualitativas absolutas que sirvan de base a los conceptos de "pesado" y "ligero" para llevar a cabo un correcto estudio del movimiento local. Todo lo necesario lo provee el nuevo escenario físico en el que los cuerpos se caracterizan de manera cuantitativa. Toda distinción se establece por vía comparativa. La velocidad de calda de un cuerpo por un medio requiere señalar (a) las cantidades puestas en juego en la comparación (peso, volumen) y (b) cuáles son los sujetos de la relación (las sustancias: un cuerpo y el medio atravesado, p.e.). Básicamente, identificando el agua y el aire como

pesados (cuya materia se dispone en un espacio menor), tenderdn a rellenar esos espacios estrechos. Pero esto es tomar como prueba aquello mismo que deseamos demostrar: lo que deseamos demostrar es esa tendencia, y no hay una razón para que los cuerpos más pesados tiendan a rellenar los espacios más estrechos, en principio, más allá de la ontología aristotélica y en el seno de la nueva interpretación. Pero, insisto, el meollo de la cuestión no se encuentra en la falta de conclusividad, sino en que Galileo no cree necesaria la prueba en este momento. 
medios con una diferencia básica en su peso relativo por volumen, el estudio de los casos en uno de ambos equivale cualitativamente al estudio de casos en el otro. Sobre esa base Galileo pone en relación los sólidos que caen con el medio por el que lo hacen. Galileo establece que la velocidad de caída en un medio como el agua es una función del peso del propio cuerpo en relación al peso de un volumen igual del medio por el cual el cuerpo cae. Del mismo modo, el lugar en el que un cuerpo permanece en reposo en el seno de un medio depende de los pesos relativos del cuerpo y del medio, tomando, como cantidades para la comparación, volúmenes idénticos del cuerpo en cuestión y del medio. (Cf. Drake \& Drabkin, 1969, págs. 338-355.) Así Galileo establece que tanto la causa del movimiento local, como el cálculo de las velocidades del movimiento natural de caída, se pueden determinar sobre tales (nuevas) bases. Es el replantamiento de una dinámica del movimiento local desde una perspectiva arquimediana estático-hidrostática ${ }^{12}$ (Solís, 1983, págs. 73-76). Pero sin salirse, eso sí, de un planteamiento causalista propiamente aristotélico ${ }^{13}$. Lo más importante es ¿con qué objetivo?

Apreciablemente, con este cambio de punto de vista facilitamos el paso hacia la matematización del movimiento. Esta es, de hecho, la transformación que pretende Galileo dentro del estudio del movimiento local hasta entonces tipificado en un escenario metodológico aristotélico: una transformación exclusivamente metodológica. Sobre ese plano, y sin trascenderlo, se iniciará el trabajo crítico y un nuevo estudio sobre el movimiento local desde un punto de vista todavía dinámico. Las consecuencias para el esquema general de las cosas en el universo son nulas.

Sobre este intento de crítica ya adelantamos algo en la segunda sección de este trabajo (cf. Drake, 1986, pág. 438). Ahora corresponde darle la palabra a Galileo acerca del papel de las matemáticas en la filosofia (natural). En un pasaje del De motu dialogus en el que critica los argumentos de Aristóteles (que van acompañados, como muestra Galileo, de "pruebas" matemáticas erróneas)

12 Las fuentes de este cambio de planteamiento aparecen en el apartado siguiente.

13 Como ya veremos más adelante en esta parte, esto no es sorprendonte en el De motu. El planteamiento de un plano de discusión en que se ha cambiado el carácter de la misma desde el plano de lo cualitativo a lo cuantitativo (mediante una reordenación conceptual - de términos, conceptos y su clase de relaciones entre ellos-), al tiempo que se mantiene el punto de vista dinámico en el estudio del movimiento corresponde a la más interesante peculiaridad del De motu. 
acerca del movimiento en función de la densidad del medio (y en el que, de paso, critica también los argumentos de Aristóteles que tratan tanto de las características del movimiento en un supuesto vacío como del vacío mismo), Galileo introduce sus propias opiniones acerca del papel de las matemáticas en el estudio de los problemas físicos, en abierta oposición a Aristóteles. Tras los argumentos correspondientes contra Aristóteles, basados en pruebas matemáticas, Galileo añade:

Domenico: ¡Qué descubrimiento tan sutil, y qué bellamente ejecutado! Seguramente serian silenciados quienes aseguran que pueden alcanzar la filosofla sin un conocimiento de las matemáticas divinas. ¿Y negará alguien alguna vez que la verdad puede distinguirse de lo falso sólo con las matemáticas como gúa, y que con su ayuda la agudeza del genio puede ser activada, y que, finalmente, con su guía cualquier cosa conocida efectivamente entre los mortales puede ser aprehendida y comprendida? (Drake \& Drabkin, 1969, pág. 368.)

(El punto de vista de Galileo queda bastante claro con sólo atenernos al subrayado. Pero si lo completamos leyendo las páginas anteriores - y las posteriores, cómo no- quedaremos plenamente convencidos.)

Así pues, la respuesta a la pregunta realizada más arriba ${ }^{14}$ sería algo así como: "solucionar ciertos problemas del movimiento local como lo haría un filósofo natural que emplea las matemáticas». Esa es la trayectoria que parece querer seguir el De motu: no hay transformación ontológica; tampoco hay transformación definitiva en las creencias; $y$ posiblemente, no existe ni siquiera tal intención por parte de Galileo ${ }^{15}$.

14 Recordemos: "icual es el objetivo final de la reforma presentada en el De motu?"

15 Galileo tenía muy en cuenta que existía una diferencia clara entre formas metodológicas dispares de tratar según qué problemas. En el Tratado de la esfera o cosmografia GaliLEo limita la labor del cosmógrafo a un tipo de tratamiento cuantitativo de las partes del mundo y lo distingue de «la consideración de la sustancia y de las cualidades de las mismas partes», cuestión cuyo estudio corresponde «al filósofo natural (Opere, vol. II, pág. 211; cit. en la introducción a GALILEO, 1630, p. xoxii, por A. BELTRAN). Algo muy similar encontramos en el De motu dialogus, cuando Galileo sefiala que «discutir el movimiento en términos generales, su esencia y diversas propiedades, (...) sería, de hecho, innecesario." Con tal objeto acudiría "al mismo Aristóteles, en su Fisica, y a todos sus comentadores." (Opere, vol. I, págs. 367-408; traducción inglesa, DrAKE \& DRABKIN, 1969, págs. 331-377; véase pág. 331.) En ambos casos debe distinguirse el 
Ya hablaremos más adelante (véase la sección siguiente) sobre cómo finaliza el De motu y cuáles son sus soluciones a los problemas del movimiento. Lo que ahora debe quedar claro es que en estos momentos Galileo trabajaba (esto lo extraemos de la orientación disciplinar - y metodológica - de sus textos) formándose como filósofo natural tanto como matemático. Esto supone una preocupación intelectual por ambos puntos de vista, y una suerte de ambigua relación con la física aristotélica. La crítica metodológica no podía actuar de abogado del diablo contra el cuerpo central de un sistema de creencias que se ve obligado a cultivar. Esto se refleja en el De motu. Como hemos visto en pequeño detalle, hay elementos creenciales básicos que no son puestos en duda, pero si profundizamos sólo un poco más en el trabajo de Galileo en estas fechas podremos contar con argumentos en favor de esta convivencia intelectual. Más tarde, en la sección siguiente podremos apreciar cómo todo ello afecta a la interpretación matemática efectuada en el De motu y al modelo de movimiento local presentado por Galileo en este texto. Veamos ahora que, de hecho, se produce esa convivencia intelectual e investigativa.

En efecto: la composición del De motu, como ya hemos mencionado, coincide con el desarrollo de los tratados sobre el universo, la alteración y los elementos que componen los Juvenilia. Siguiendo a Stillman Drake, de nuevo (Drake, 1986, pág. 440), señalaré que el «Tratado sobre el universo (y los cielos)" (Wallace, 1977, págs. 35-158) es escrito unos dos anios antes que el $D e$ motu dialogus (1586-87). $\mathrm{Y}$ uno o dos ańos después de haber adoptado la postura metodológica que he descrito para el De motu dialogus, Galileo escribe los tratados sobre la alteración y los elementos (Wallace, 1977, págs. 159-251), que entran, como el primero de los tratados, dentro de una estricta ortodoxia jesuítica, (en la que perviven, sólidamente asentadas, algunas de las bases de la fisica y la metafísica aristotélicas ${ }^{16}$ ). Tras ello se atrevió con nuevos ensayos

tipo de discusión filosófica, con su propio método de argumentación y criterios de validez, del tratamiento matemático, cuantitativo, de cuestiones locales, como los problemas de la cosmografla y el movimiento en el mundo sublunar, con otro método y criterios de validez. Galileo era muy consciente de que cada tipo de problema requería un tratamiento específico. La consciencia galileana de la distinción es fundamental para nosotros, pues ahí puede situarse la pretensión de Galileo de una interpretación arquimediana del movimiento local sin tener por qué renegar de las creencias cientificas aristotélicas (por lo menos en un principio); ahí se sitúa la condición de posibilidad del cambio que aquil estudiamos.

16 Aunque es en la comunidad jesuítica en la que surge una forma ainternaw de crítica a Aristóteles, tanto desde el punto de vista metodológico (apreciaban el valor de las matemáticas y hubo buenos matemáticos entre sus filas, como Clavius) como conceptual. 
sobre el movimiento, escritos en Florencia y en Pisa antes de 1591, con la misma orientación que el De motu dialogus ${ }^{17}$.

Los textos de los Juvenilia nos revelan la imagen de un Galileo pleno en su conocimiento de la filosoffa natural de Aristóteles. Galileo no emplea otro método que el discursivo en solucionar las cuestiones que se plantea en los distintos tratados. Sigue un esquema de exposición de doctrinas aristotélicas e interpretaciones según diversos autores clásicos, réplicas a dichos argumentos, ajenas y "propias" (propias de profesores del Collegio Romano de cuyos argumentos se apropia frecuentemente; cf. Wallace, 1977, introducción), contrarréplicas y, a menudo, ciertas conclusiones finales. El vocabulario es plenamente aristotélico, y el modo de demostrar la validez de las argumentaciones suele seguir el esquema de los Analiticos Posteriores de Aristóteles (fuente que cita en el tratado introductorio: Wallace, 1977, págs. 28-29). Los tratados versan sobre los aspectos principales de la doctrina aristotélica tal y como ésta se presenta en De caelo, De generatione et corruptione y también en la Fisica.

Poco más podremos decir que no implique estudiar a fondo cada cuestión de los tratados. Oponer el trabajo de Galileo en ambos grupos de escritos no es más que presentar la ortodoxia aristotélica frente a un tratamiento plenamente dispar en cuanto a metodologia y objetivos (pese a ser obra de una misma pluma ${ }^{18}$ ). La disparidad metodológica ya parece haber quedado clara

17 Señala Drake que con posterioridad a esos dos tratados de los Juvenilia, Galileo redactó un ensayo sobre el movimiento en Florencia (el De motu florentino de Drake, cf. DRAKE 1986) hacia 1588. Posteriormente escribió unas "cuestiones lógicas", la citada Demostración en la ciencia, con una orientación muy marcada de los análisis de la lógica del conocimiento y de la demostración científica de Paolo VaLla (conferencias en Roma 1587-1588, de las cuales muy posiblemente Galileo puedo disponer de una copia que Valla repartió a sus oyentes). Galileo tenía a Valla en muy alta estima (DRAKE, 1986, pág. 444), por lo que en ese mismo año revisó su ensayo sobre el movimiento redactado en Florencia, haciendo especial hincapié en el orden lógico en detrimento de los tintes metafisicos. Todo lo aquil mencionado ha sido extraido de Drake, 1986, en particular de las págs. 432-435 y 444. Creo que merecia la pena incidir sobre ello, pues nos revela un aspecto más de las "pequefias" pero importantes transformaciones que afectan al método cientifico de Galileo (sin tocar el status creencial vigente), en estos años previos al final de la penúltima década del siglo XVI. Una fuente 'interna' de variación (interna a la ortodoxia jesútica).

18 Aunque deberiamos decir que por esa pluma caen las tintas de muchos y variados profesores del Collegio Romano (WALIACE, 1977, págs. 12-21). Estando Galileo por estos afios formándose como profesor con miras a conseguir una plaza de profesor universitario (DRAKE, 1986, págs. 435-436), poco más apropiado podría encontrar que seguir fielmente las disciplinas aristotélicas corrientes en los entornos académicos. Wallace aduce un gran trabajo de comparación (realizado por él mismo a lo largo de varios años) de las comunicaciones de los jesuitas y los Juvenilia 
con lo mencionado aquí hasta ahora a propósito de cada trabajo de Galileo por separado: la metodología presentada en el De motu no tendría cabida en los Juvenilia ${ }^{19}$. En cuanto a los objetivos, si bien ya se aprecia la diferencia de búsquedas, podemos profundizar algo más en ellas. Al comienzo del De motu dialogus dice Galileo, en boca de Domenico:

Domenico: Ahora creo que una conversación acerca del movimiento no sería desagradable. Sin embargo discutir el movimiento en términos generales, su esencia y muchas propiedades, llevaría demasiado tiempo y sería, de hecho, innecesario. Porque cuando quiera complete tratamiento de este asunto. consultaré al mismo Aristóteles, en su Fúsiç y a todos sus comentadores. $\mathrm{Y}$ así, ahora me restringiré a un único tipo de movimiento, a saber, el movimiento de los cuerpos pesados y ligeros. (Drake \& Drabkin, 1969, pág. 331. Subrayado mío.)

Con esto podemos observar, sobre todo por el subrayado, que Galileo tiene muy clara una división entre tratamientos, dentro de la ortodoxia de la filosofía natural de Aristóteles, de los asuntos acerca de la esencia y propiedades fundamentales del movimiento (i.e., como todo proceso de cambio, en general, lo que incluye el crecimiento de las plantas y todo otro proceso de alteración en un sentido aristotélico: todo cambio de cualidad) y un planteamiento como el que va a llevar a cabo en el De motu: problemas que posibilitan la mencionada tentativa de revisión metodológica. Un problema sobre la esencia del cambio no es tratable matemáticamente, pero las causas físicamente contrastables del movimiento local, en lo referido a la ligereza o pesantez de los cuerpos, pueden estudiarse (o por lo menos así lo parecía en un principio) desde un punto de vista matemático sin que ello sea un atentado

galileanos que viene en apoyo tanto de su reconstrucción cronológica como de contenidos, así como de los origenes jesuíticos de tales contenidos (WALLACE, 1977, 1981). Los tratados de los Juvenilia pueden ser tomados como los ejercicios obligados del filósofo natural del momento. Esto viene en apoyo de todo lo que venimos diciendo: no habra un deseo innato inicial de supuesta ruptura en Galileo. Las creencias aristotélicas calan en él lo suficiente como para que transluzcan en sus primeros escritos metodológicamente más urebeldes» y como para que se puedan ver como parte de su (asumido) proceso de aprendizaje.

19 Como he mencionado en una nota anterior (véase nota 15), Galileo parecía tener clara la diferencia entre el trabajo de un filósofo natural y el de un matemático o, por lo menos, cuando parecía corresponder aplicar los métodos y enfoques de uno u otro, según los objetivos del estudio. 
contra el sistema de creencias científicas aristotélico: es sólo una correccion, no una suplantación.

Así pues, la diferencia en los objetivos de cada estudio galileano en los textos distintos del De motu y de los Juvenilia es paralela a una disparidad en los planteamientos metodológicos que el propio Galileo debía considerar posibles. Yo diría, incluso, que la primera distinción implicaba la segunda y que habla una correspondencia directa entre objetivos y métodos. Por eso Galileo se introduce en el trabajo comenzado en el De motu con toda naturalidad y, más aún, sin renegar de sus creencias de base: de los principios de "sentido común" rectores de su investigación científica.

Con ello volvemos a recalar en el punto del que partfamos y cuyo semblante hemos visto en pasados párrafos: Galileo poséa unas creencias cuya reforma metodológica no parecía llegar a tocar. Las razones básicas (intuitivas) de la ordenación del universo forman parte de esas creencias, y junto a ello hay un proyecto de investigación marcado por una prioridad clara que no se rechaza y que es plenamente aristotélica, la búsqueda de las causas (del movimiento local, en este caso). Con ello, en fin, atracamos en el puerto de las creencias básicas de la ciencia aristotélica. A Galileo le interesa la filosofía natural, le interesa Aristóteles, tanto como lo hace Arquímedes y los tratamientos matemáticos de problemas físicos. Como señala Drake, "su desviación hacia las matemáticas y los problemas del movimiento no habián disminuido su interés en la filosofía natural.» (Drake, 1986, pág. 443.) Su base creencial estaba en Aristóteles. Por mucho que apasionen nuevos métodos y trabajos, es difícil desprenderse del mundo en que uno ha ubicado su propia existencia y, más en concreto, sus creencias científicas.

Hemos atendido a la convivencia de un sistema de creencias con un plan de reforma metodológica, a lo que se suma la fusión de ambos en un sólo texto. Debemos profundizar más en ello, pero no podemos dejar de lado un aspecto crucial en esta historia, que debemos tratar inmediatamente. Lo que a continuación veremos será el reducto de conocimientos que influyen en Galileo al margen de (o junto a) su basamento creencial aristotélico. Existe en la Italia del siglo XVI un grupo de tradiciones en mecánica que se distinguen por sus fuentes, planteamientos y métodos entre sí. Estas tradiciones tienen como base a Aristóteles, pero muchas de ellas apenas si lo contemplan o se puede apreciar en sus resultados. Para ver cómo influyen en Galileo comenzaremos por introducir la filosofia natural aristotélica entre un grupo de tradiciones frente a las que 
no se presenta, ni mucho menos, como primus inter pares (haciendo abstracción de su responsabilidad como cimiento creencial de la ciencia). Por decirlo de una manera clara, ¿qué otras opciones metodológicas se presentan a Galileo al margen de la ortodoxia académica aristotélica? Al nivel de los planteamientos y enfoques de los problemas ffsicos y sus métodos resolutivos, el aristotelismo encontraba un cierto número de competidores que participaron, de cara a la elección metodológica de Galileo, como opciones posibles de tratamiento de una determinada cuestión como es el movimiento local. Como venimos señalando, la opción adecuada acabó siendo un modo de tratamiento alternativo (: el matemático-arquimediano, cuya sombra se extiende por las tradiciones que veremos a continuación). Podríamos argumentar, además, que la sola disponibilidad de un conjunto de tradiciones metodológicamente alternativas a la aristotélica debió actuar en pro de una consideración galileana acerca de un planteamiento metodológico diferente al modo de tratamiento aristotélico de los problemas físicos. Pero esa es otra historia. Veamos tales opciones.

\section{Nuevas y viejas fuentes}

El proceso de cambio inaugurado en el De motu se extenderá por la práctica totalidad de los trabajos futuros de Galileo como una semilla sembrada en el terreno apropiado. En los siguientes párrafos exploraremos dónde se originó tal proceso de cambio, intelectualmente hablando: de dónde proviene la semilla. Veremos, pues, aquel grupo de tradiciones que no presta un servicio como generador de un escenario metafísico determinado (pues muchas de ellas poseen el mismo escenario aristotélico tradicional), sino como origen de la alternativa caracterizada por la brisqueda de soluciones matemática y fenoménicamente expresadas.

En efecto, las soluciones que durante largo rato vinimos presentando páginas atrás debian tener un origen en algún punto del aprendizaje de Galileo. Tal aprendizaje estaba constituido por diferentes técnicas de tratamiento y resolución de cierta serie heterogénea de problemas de índole práctica y teórica. Técnicas que podemos encontrar en un conjunto de tradiciones de diferente origen que recalaron, todas ellas, en la península italiana a lo largo del siglo XVI.

Realiza Stillman Drake una diferenciación en tradiciones de la mecánica de la que ya hemos hecho mención con anterioridad. (cf. Drake \& Drabkin, 1969, págs. 5 y sigs.) Vamos a seguir un orden distinto al de Drake dejando 
de lado, además, alguna tradición ${ }^{20}$. En primer lugar debemos tratar una de las tradiciones más influyentes: aquella que presenta como obra fundamental las Cuestiones de Mecánica, texto erróneamente atribuido a Aristóteles en estas fechas ${ }^{21}$. En las Cuestiones se tratan problemas del movimiento y de la aplicación de la fuerza desde un punto de vista dinámico (incluyendo el más clásico problema de la estática como es la balanza). Observamos una discusión cualitativa sobre principios dinámicos, dejando de lado un posible punto de partida basado en distinciones cuantitativas (un punto de vista que conduciría a métodos de resolución matemáticos). La presunta autoría aristotélica y esta forma de tratar los problemas hizo que las Cuestiones, conocidas en Italia desde la segunda década del XVI (Drake \& Drabkin, 1969, pág. 11) encontraran en ese siglo una dura oposición por parte de los matemáticos con una orientación más claramente arquimediana (Wisan, 1974, pág. 133). No obstante, si hemos de hacer caso a Winifred Wisan, esta tradición del pseudo-Aristóteles, junto a otro texto atribuido a Euclides, proporcionaron herramientas conceptuales básicas a Galileo en su propio trabajo ${ }^{22}$.

Frente a esta tradición aristotelica antigua (según la denominación de Drake, 1969), podemos situar otra tradición que posee también como fuente

20 Por ejemplo la de Herón y la tradición tecnológica. Sobre ambas me remito a DRAKE \& DRABKIN, 1969, págs. 5 y sigs., pero no hablaré de ellas porque considero que serfa extender innecesariamente el contenido de esta sección. Su influencia educativa sobre Galileo nos toca, de momento, sólo de soslayo.

21 Drake sefiala que posiblemente fue escrito por un alumno suyo o por Arquitas de Tarento. Cf. DRAKE, 1989, pág. 53, nota 69.

22 El texto atribuido a EUCLIDES es El libro de Euclides sobre lo pesado y lo ligero y sobre la comparación de unos cuerpos con otros. Ahí podemos encontrar una serie de postulados de partida verdaderamente sugerentes. Para empezar, el término "fuerza" no es distinguible de "velocidadw. Así aparece en la Física de ArISTÓTELEs (VI, 4, 249b), en las Cuestiones y en El libro de Euclides. Tras ello, ciertos postulados de los que nos habla WISAN (1974, págs. 132-133) parecen interesantes: P1-los cuerpos cuyo movimiento a traves de lugares iguales (medios) se producen en tiempos iguales, son iguales en fuerza; El postulado P2 es el exactamente inverso a éste (si tales cuerpos atraviesan lugares iguales en tiempos diferentes, son dispares en fuerza), pero el P3 nos recuerda a algo que, invertido, ya vemos en el De motu: P3-Son cuerpos de igual clase aquellos que, poseyendo igual volumen son de igual fuerza. Por último el P4 enlaza con la creencia galileana basada en Aristóteles que velamos en el apartado anterior: Los cuerpos más sólidos son los de mayor capacidad (o los de más «intensidadu): Esto puede ser un origen (aristotélico probablemente) de la caracterización de los cuerpos sólidos como aquéllos con más cantidad de materia en menos espacio y como aquellos que caen más rápidamente en cualquier medio. Pero es una discusión para la que carezco de datos, asi que la dejaré aquí. Sobre todo lo aquí dicho, cf. WISAN, 1974, págs. 132-133. 
a Aristóteles; o mejor, a otro texto suyo: la Física. La tradición de la Física es fundamentalmente medieval. En ella, y durante el medievo latino, se desarrollaron los conceptos y herramientas fundamentales que vamos a ver repartidos en el (ortodoxamente académico) estudio del movimiento: el impetus, la virtus impressa, y el teorema de la velocidad media del Merton College de Oxford hacia el final de la Edad Media ${ }^{23}$. Esta tradición estudia las cuestiones generales de la física aristotélica, empleando un tipo de razonamiento lógico y, frecuentemente (como es el caso del Merton College), también matemático. En estos estudios notamos ya una oposición temprana a Aristóteles que, sin salirse del campo de las creencias aristotélicas, se limita a aclarar y pulir algunos de los rincones menos claros del aristotelismo ortodoxo. Tal es la tradición que llega a Galileo de la mano de los jesuitas del Collegio Romano y que ocupa lo que hemos llamado 'formación como filosofo natural' de Galileo (Wallace, 1977, 1981 y 1984, págs. 3-202) ${ }^{24}$.

En tercer lugar, tras la recensión de contenidos de las tradiciones que emplean como textos-fuente los de Aristóteles, hemos de hablar del estado del conocimiento de otros autores antiguos como Euclides y Arquímedes. Euclides es un autor más o menos bien conocido durante el siglo XV. Los Elementos, la Optica y la Catóptrica, por ejemplo, habían llegado a la Europa cristiana de manos de los traductores árabes a mediados del siglo XII (Crombie, 1974, 1, págs. 46-47). Los Elementos (Hutchins, 1982, págs. 1-396) suministran el canon de la demostración geométrica y de la manera adecuada de construir una teoría axiomátizada (cf. Vega, 1986, pág. 24). Al margen de las influencias arquimedianas, el conocimiento de tales textos se convierte en fundamental para todo matemático que se precie, sea cual sea el empleo que haga de la geometría. Con todo, los Elementos sufrieron una grave deficiencia en su libro V la cual, por la hegemonla educativa del texto, supuso una deficiencia a nivel general en el conocimiento matemático del momento (cf. Drake, 1989, págs. 23-25). Ahí, en las definiciones 4 y 5 (Hutchins, 1982, pág. 81) podemos

23 Sobre la génesis y desarrollo de estos conceptos, cf. SAMBURSKY, 1990, págs. 83-90; CROMbie, 1974, 2, págs. 50-98; y KuHN, 1978, págs. 165-171.

24 La teoría del impetus será también la adoptada por BENEDETTI para explicar la aceleración en caida libre en su Diversarum speculationum, Turín, 1585, algo que lo separa de Galileo (que ya en el De motu proporciona su propia explicación según una tradición de Hiparco, Juan Filopón y Francisco de Marchia), partiendo ya de Tartaglia, que nunca hizo demasiado caso a esos asuntos filosóficos. Particularmente interesante e ilustrativo es el capículo dedicado a la mecánica del XVI de Drake, 1989, del que he extraido estos datos (págs. 23-33). 
hallar actualmente una teoría general de las razones y de la proporcionalidad de magnitudes continuas. La definición 4 parece ser de Eudoxo de Cnido (algo que probablemente no conocía Aristóteles, a diferencia de su conocimiento de las esferas homocéntricas; cf. Drake, 1989, pág. 23 y nota 32), mientras que la definición 5 sería del propio Euclides ${ }^{25}$. El texto medieval no disponía de tal teorla, sustituida (y la razón no está clara) por la teoría medieval de la proporción. El valor de tal parte antigua se encuentra en el riguroso tratamiento de la proporcionalidad entre magnitudes matemáticamente continuas, como las distancias, los tiempos y las velocidades, por ejemplo. Euclides presenta ahí la posibilidad de que una circunferencia posea una razón a su diámetro (donde "tener un razón" es presentar una posible condición de proporcionalidad) ${ }^{26}$. Esto era capaz de modificar uno de los principios básicos de Aristóteles, según el cual no podía haber una razón entre la curva y la recta (Drake, 1989, pág. 25). Drake señala que "para las matemáticas, una consecuencia era la rectificación de las curvas; para la física, el abandono de dogmas aristotélicos tales como el de un abismo necesario entre los movimientos circulares celestiales y los movimientos rectos elementales" (Drake, 1989, ibid.). Sólo un Tartaglia, que desconocía el griego pero tenía la suficiente intuición matemática para llevarlo a cabo, pudo devolver a su forma original el texto del Libro $\mathrm{V}$ de Euclides, trasladando la teorfa medieval de la proporción a los últimos libros sobre aritmética, donde les correspondía (Drake, 1989, ibid.). Lamentablemente, tal texto, traducción al italiano de Tartaglia, con las modificaciones oportunas, no era empleado en las universidades, donde se continuaba estudiando la teoria medieval de la proporción. Pero Galileo, que fue alumno de Ostilio Ricci, el cual empleaba ese texto de Tartaglia en sus clases (pues habia sido a su vez alumno de éste), sí alcanzó a aprender tal teoría. Ésta influiría mucho en su desarrollo de la ley del péndulo, clave en el descubrimiento de la ley de caída libre ${ }^{27}$.

Por su parte, las obras de Arquímedes aparecieron traducidas en Italia desde mediados del siglo XVI, en lo que respecta a la tradición arquimediana en la

25 Luis Vega aclara, refiriéndose a los contenidos del Libro V de los Elementos, que podemos encontrar en él kuna primicia de explicación teórica precisa de la noción intuitiva de proporcionalidad implantada en la tradición matemática griega. A esa explicación contribuyen sefialadamente Eudoxo, Euclides y Arquímedes." (VEGA, 1986, págs. 26-27.)

26 Para una caracterización más exhaustiva de estos contenidos y sus implicaciones, cf. VEGA, 1986, págs. 24-27 y, en general, toda la introducción a El método de Arquímedes.

27 Cf. DRAKE, 1989, págs. 25 y 40-43. No son descartables otras influencias, por supuesto. 
ciencia de la mecánica, con sus textos principales, Sobre el equilibrio de planos (en Hutchins, 1982, págs. 502-519) y Sobre los cuerpos flotantes (Hutchins, 1982, págs. 538-560; sobre las traducciones, cf. Drake \& Drabkin, 1969, págs. 11-12). Estos textos no fueron conocidos en la Edad Media lo suficientemente bien. Sólo afectan sus estudios sobre hidrostática a la ciencia medieval del peso, tradición encabezada por los escritos de Jordano Nemorario (Wisan, 1974, págs. 134-135). Pero la influencia de Arquímedes en las tradiciones Italianas del siglo XVI es suficientemente grande y decisiva como para tomarlo como influencia fundamental en la génesis de la Revolución Cientifica (empezando por la que ejerció sobre Galileo a través de esas tradiciones). Pero, ¿cual es esa influencia?

Arquímedes empleó la geometría en el tratamiento de ciertos fenómenos mecánicos, corrientes en la filosofía natural griega. Luis Vega, en la introducción a su edición en castellano de $E l$ método de Arquímedes señala que "los aristotélicos tendían a explicarlos bajo supuestos dinámicos (...), y cinemáticos, (...). Arquímedes adopta una perspectiva estática orientada por ciertos supuestos métricos." (Vega, 1986, págs. 15-16.) Mediante la introducción de consideraciones estáticas en la fase de investigación, descubre relaciones que, más tarde, trata de demostrar geométricamente, aunque, señala Luis Vega (1986, pág. 25), sus procesos de axiomatización de la estática parecen no seguir fielmente un esquema como el de los Elementos. Un buen ejemplo de ello es el Libro I de Sobre el equilibrio de planos (Hutchins, 1982, págs. 502-509). Si nos circunscribimos a su estática e hidrostática, Arquímedes intentó presentar una forma alternativa a la dinámica aristotélica de enfocar y resolver problemas mecánicos. La aportación de Arquímedes a la mecánica es sumamente original. Supone planteamientos renovadores y, sobre todo, un punto de confluencia de la geometría y la mecánica, cuando ambos venían siendo itinerarios investigativos abiertamente opuestos desde una perspectiva platónico-aristotélica. Arquímedes «tal vez prefiere enlazar más directamente con el genio matemático creador del siglo IV representado por Eudoxo" que "desarrollar la estructura metodológica de la matemática establecida" (Vega, 1986, pág. 25). En ello radica su aportación principal al estudio de los problemas mecánicos; una aportación que se mantuvo viva en algunos de los textos de los que Galileo pudo disponer en su aprendizaje como matemático.

Para finalizar hagamos una pequeña reseña de la ciencia medieval del peso: la tradición de Jordano Nemorario, según Drake, (Drake \& Drabkin, 1969, pág. 8). Como nos señala Wisan (1974, págs. 137 y sigs.) hay dos fuentes claras en 
esta tradición: el Liber karastonis, una traducción de un tratado romano sobre la balanza, y los textos de Jordano Nemorario, los Elementa Jordani super demonstrationem ponderum, y el Liber Jordani de ratione ponderis. La ciencia medieval del peso se compone de un cuerpo ecléctico de conocimientos y de problemas tratados desde un enfoque que continúa en parte la tradición de la Física de Aristóteles. Jordano parte de los modos de explicación del movimiento en la naturaleza de corte aristotélico; de ahí toma algunas ideas que plantea como postulados, y sobre ellos se dedica a resolver problemas sobre el peso y el equilibrio llevando a cabo procesos de deducción matemática dentro de un modelo claramente euclidiano. Además Jordano aportará pruebas para alguno de sus teoremas que habían sido primitivamente proposiciones arquimedianas (Drake \& Drabkin, 1969, págs. 8-9). Los postulados de partida serán aristotélicos, pero, sefiala Drake (ibid.), uno de los logros de la ciencia medieval del peso fue salvaguardar el método arquimediano en un mundo plenamente aristotélico, como era el siglo XIII. Sólo el siglo XVI, y en particular Galileo, lo harán resurgir al lado de un - todavía fuerte- aristotelismo ${ }^{28}$.

Este es el grupo fundamental de tradiciones que llegaron a la Italia del siglo $\mathrm{XVI}$ e influyeron en los matemáticos de manera más decisiva. El foco del que han partido las que han sido vistas como influencias fundamentales es Arquímedes; pero como podemos ver no se le queda a la zaga ni Aristóteles ni Euclides. Si a ello le sumamos que no son ni el mismo Arquímedes, ni el mismo Aristóteles, ni (esto es más sorprendente) el mismo Euclides, los que llegan a todos y cada uno de los autores de estas tradiciones, el mapa de influencias posibles en Galileo es muy variado. En efecto, en cada tradición se emplean partes de estos autores que no quedan intactas al atravesar la criba de las mismas. Tanto en la tradición de la ciencia medieval del peso, como en las escuelas de mecánica italianas del XVI, Arquímedes se emplea parcialmente y

28 El papel de la ciencia de Jordano Nemorario en la de Galileo viene dado por el desarrollo de ciertos postulados de los Elementa que influirán sobremanera en Tartaglia. Ambos autores, Jordano y Tartaglia, tratarán de obtener las condiciones de equilibrio de la balanza partiendo de conceptos dinámicos como el peso y la velocidad de descenso (Jordano) o el peso, la gravedad específica y las velocidades de ascenso y de descenso (Tartaglia). A Galileo le interesará obtener precisamente la fuerza (o velocidad) en el descenso por planos inclinados, para lo cual partira, precisamente, de las condiciones de equilibrio de la balanza. Estamos en el De motw todavía, pero considerando el papel de los posteriores experimentos (1603-1604) con el plano inclinado en el desarrollo de la ley del péndulo y de la ley de carda de los cuerpos (DRAKE, 1989, págs. 35-37), el conocimiento galileano de la ciencia medieval del peso parece igualmente fundamental (cf. WISAN, 1974, págs. 150-151). 
de un manera muy específica para objetivos también muy definidos ${ }^{29}$. Así pues sería el objetivo de un sólo estudio establecer tales influencias de forma sólida.

Como ya dije, nos interesa destacar el papel de esta serie de tradiciones como «educadoras" de Galileo en una serie de técnicas de resolución de problemas (o de alcance de soluciones, como queramos) y en un enfoque metodológico general, alternativos ambos a los aristotélicos (criterios de validez incluidos). Las discusiones acerca del movimiento en el marco de la universidad tomaban tintes de argumentación escolástica medieval, dentro de la tradición de la Física de Aristóteles. Pero a través de la matemática de las escuelas italianas de mecánica, empleada para resolver problemas prácticos tanto como teóricos, Galileo podía descubrir, junto a los recursos técnicos-matemáticos disponibles y al bagaje de conocimientos sobre mecánica acumulado, un plano de la discusión que se cinera a resolver problemas especificos del movimiento de los cuerpos, sin tener que atender a los problemas filosbficos sobre la esencia del movimiento. Galileo podía aprender esto de, por ejemplo, un Tartaglia ${ }^{30}$ que

29 Drake distingue dos escuelas Italianas de mecánica: la Escuela del Norte de Italia, con Tartaglia, Cardano y Benedetti en cabeza, y la de Italia Central, con matemáticos como Commandino, Guidobaldo del Monte y Bernardino Baldi. La primera, preocupada por los aspectos más prácticos de la mecánica, habría captado la parte más conveniente de Arquímedes a sus objetivos y habría tomado la ciencia medieval del peso como el reemplazo perfecto de la tradición de las Cuestiones de Mecánica (en creencia de que eran aristotélicas). La segunda, ocupada en asuntos de orden más teórico habría echado mano del Arquímedes de los tratados matemáticos, y habría visto imposible superar el trabajo de los antiguos en mecánica. Esto es una segunda criba de Arquímedes, Aristóteles y Euclides, ya transformados por las tradiciones y traducciones medievales (DRAKE \& DRABKIN, 1969, págs. 13-16).

30 Pese a lo que diré a continuación (o, más bien, de acuerdo con ello), la pugna tébrica de TARTaglia en la Nova Scientia o en los Quesiti et inventioni diverse se mantiene con el aristotelismo. El manto creencial aristotélico permanece vivamente presente en las tradiciones del siglo XVI de uno u otro modo, tanto si uno era filósofo o era matemático, si era académico o no -como es, este último, el caso de Niccold Tartaglia, que creo que puede servir bastante bien de ejemplo. Un buen estudio de ambas obras de Tartaglia es el de Alexandre KoYré uLa dinámica de Niccold Tartagliax (KOYRE, 1977, págs. 103-124). Las obras citadas de Tartaglia están traducidas al inglés, con un buen tratamiento introductorio, en DRAKE \& DRABKIN, 1969. Drake realiza en tal introducción a las obras de los matemáticos de XVI una serie de distinciones de tradiciones antiguas, medievales y modernas en mecánica que obligan a especificar ese karistotelismow arriba citado. Debemos decir que la pugna teórica debió mantenerse con los elementos teóricos sobre movimiento local extraídos de la fuente de una tradición *aristotélicas (antigua), como son las pseudo-aristotélicas Cuestiones de Mecanica y cuyos tratamientos eran dinámicos y cualitativos, y también con la tradición «peripatétican (medieval) o «filosofia del movimienton que mantenía un desarrollo de los puntos básicos de la ciencia del movimiento según la Física 
se ocupaba de diversos problemas, pero siempre desde un punto de vista exclusivamente matemático. Como señala Koyré (1977, págs. 103-104),

Tartaglia parece querer evitar toda discusión filosófica a propósito de los conceptos que emplea - movimiento natural y violento, etc.-, así como toda discusión relativa a las causas de los fenómenos que está estudiando. Así, no plantea nunca la pregunta: a quo moventur proiecta?, ni menciona la existencia de teorías rivales - la de Aristóteles y la del impetus- que explican de modos diferentes la acción del motor en el móvil, en el caso del movimiento violento, o la aceleración espontánea de los cuerpos graves en el movimiento natural. Él procede modo geometrico, comenzando por dar una serie de definiciones, a las que siguen suposiciones (axiomas) y juicios comunes de los que finalmente deduce las proposiciones de la ciencia nueva.

Tartaglia evita, en su Nova scientia y en sus Quesiti et inventioni diverse, la perspectiva filosófica, explicativa, universalista. (Tartaglia no era un universitario, sino un matemático formado de manera independiente.) Muy al contrario, lleva la discusión al terreno que domina, un terreno geométrico, matemático, en el que se tratan muy específicos problemas físicos locales. Como señala Koyré, «son justamente datos y conceptos empíricos — por lo menos es lo que él cree- lo que quiere someter a un tratamiento matemático (geométrico) sin pasar por una teoría explicativa que formaría su unión." (Koyré, 1977, pág. 104). Galileo pudo aprender esta perspectiva en sus clases con el alumno de Tartaglia, Ostilio Ricci. Y, si bien la orientación de Tartaglia se ocupaba de asuntos de mecánica más prácticos, Galileo mantuvo por otro lado correspondencia con Guidobaldo del Monte, un matemático perteneciente a una escuela ocupada en los aspectos más teóricos de la mecánica. Galileo dispuso de focos educativos donde aprender acerca de las posibilidades de tales planteamientos. $\mathrm{Si}$ buscamos fuentes educativas de la transformación iniciada en la interpretación matemática del De motu hemos de profundizar en las revisadas en este subapartado, pues, siguiendo las tesis de Wisan (1974, págs. 146-150), fue de

de ARISTOTELES (DRAKE \& DRABKIN, 1969, pp 5 y sigs.). No obstante el método de Tartaglia sigue fielmente los pasos metodológicos de la tradición de Jordano Nemorario, la «ciencia medieval del peso" (WISAN, 1974, págs. 146-147), la cual, asentada sobre la base dinámica que proporciona la Física de Aristóteles, elige algunos de sus planteamientos como postulados de partida para extraer deducciones matemáticas siguiendo un esquema metodológico definitivamente euclidiano. (DRAKE \& DRABKIN, 1969, ibid.) Mís información pertinente sobre Tartaglia en DrAKE \& DRABKIN, 1969, págs. 16-26 y en DRAKE, 1989, 24-28. 
ellos de donde Galileo extrajo los conocimientos necesarios para el nuevo enfoque metodológico que iniciaba en el De motu.

En la siguiente sección veremos cómo, cuando Galileo desarrolle su interpretación matemática del movimiento en el De motu (en el que persisten como participantes activos las creencias aristotélicas, a pesar de su inicial declaración de intenciones sobre no tratar los problemas de la esencia del movimiento), percibirá que las soluciones adecuadas a ciertos problemas, en particular el de la aceleración natural del movimiento, requieren una aceptación plena de ese nivel de abstracción modo geometrico, como dirla Koyré. En efecto, Galileo no podrá romper con el empleo de concepciones del movimiento que se encuentran justificadas sólo en un sistema de creencias aristotélico. Su utilización en un planteamiento metodológico renovado conllevará algunas de las contradicciones de las que vamos a hablar en la sección siguiente con el debido detalle. Cuando Galileo, para dar con las soluciones apropiadas a tales dificultades, radicalice su planteamiento metodológico y lo desarrolle, prescindiendo entonces de discutir los problemas del movimiento local sobre el terreno mismo de las creencias ${ }^{31}$, dará un paso con aparente trascendencia sólo en el plano metodológico, pero con una afectación mucho más profunda cuyos resultados se dejarán notar a la larga. A partir de entonces ya nada, en las creencias científicas aristotélicas, podrá continuar siendo igual. El cambio en el sistema creencial se convertirá en un paso necesario, aunque darlo en su totalidad ya no le corresponderá a sólo él.

De la aceleración accidental a la aceleración natural: crónica de un pequeño-gran salto

Tras presentar en qué consiste el paso interpretativo del movimiento local por Galileo en el De motu, la intima dependencia del sistema de creencias aristotélico y las fuentes metodológicas (alternativas a éste) del nuevo enfoque,

31 No es que Galileo prescinda completamente del modo filosófico de discusión -que reanuda en ciertos momentos, como en la Primera Jornada del Dílogo (Gallleo, 1632, págs. 9-94), aunque con argumentaciones apoyadas en su nuevo modo de investigación-, sino que hace $a$ un lado las consideraciones creenciales para tratar los problemas del movimiento en un terreno de cierto aislamiento respecto de éstas (tanto en el terreno metodológico como en el fenoménico). 
fuentes también de los recursos técnicos necesarios para el mismo, debemos describir las soluciones de Galileo a los problemas sobre el movimiento que se presentan en aquel texto: los frutos de la interpretación galileana (teniendo en cuenta tales condiciones preliminares). A este primer paso, en el que la tímida incursión de una reforma metodológica no acaba de resultar plena de coherencia, le siguió otro de radicalización de dicha reforma. Durante su segundo periodo Galileo no suele emplear los procedimientos de discusión filosófica empleados de forma corriente para tratar asuntos de índole ontológica (como los que trata en los Juvenilia; cf. Wallace, 1977). Entre otras cosas, los asuntos que ocuparon su tiempo a partir de entonces estaban muy poco relacionados con los problemas tocantes a las causas y las esencias de los fenómenos. En cuanto a las cuestiones de las que ya se venía ocupando desde mediados de la década de los ochenta del siglo XVI, relacionadas con el movimiento local, tal y como hemos apreciado suficientemente, en ellas ya habla tratado de prescindir de las alusiones directas y/o finales al terreno de lo ontológico, profundizando en un plano de discusión que no tenía intención de trascender lo fenoménico. Tal proyecto estaba motivado por un plan de reforma metodológica, no por una intención consciente de rechazar por completo el sistema de creencias aristotélico; paso que hubiera sido contraproducente, dada su educación como filósofo natural. La alternativa metodológica conllevaba un punto de vista que implicaba un aislamiento (metodológicamente motivado) respecto del terreno del conjunto de creencias aristotélicas sobre el mundo, tanto en la investigación como en la argumentación. Aislamiento que, como ya sabemos (y por ese perfil de "filósofo natural" al que me he referido), no llegó a consolidarse en el De motu. Galileo dependía más de las ideas aristotélicas sobre el mundo que de las apreciaciones observacionales de los fenómenos. Durante la última fase Galileo buscó prescindir todo lo posible de tales ideas aristotélicas pertenecientes al sistema de creencias. En lugar de ver a través del filtro aristotélico, llevó a cabo un intento de fundamentación del estudio de la física directamente sobre los fenómenos. Para ello desarrolló un aparato metodológico completo en el que las suposiciones deblan mostrar una clara y expresa cercanía a los fenómenos por vía de la experimentación. Los fenómenos serían el objeto de tratamiento cuantitativo, con lo que eran susceptibles de manipulación matemática. Así, por lo menos en cuanto a la intención de Galileo, la aceptación tácita de la verdad de unas creencias aristotélicas desaparecía como posibilidad de fundamentación en el estudio de los fenómenos físicos: dejaba de haber un lugar oficial para las creencias aristotélicas dogmatizadas. 
Para alcanzar a ver el proceso que venimos anunciando, esto es, la elección de Galileo de dar prioridad al desarrollo de soluciones según un diseño matemático de los problemas, haciendo a un lado ciertos elementos creenciales tradicionales (de la tradición de la filosofía del movimiento ${ }^{32}$ ), debemos fragmentar el estudio de la génesis de esta segunda fase de Galileo. Comenzaremos por estudiar las contradicciones más visibles del De motu, para buscar una imagen comprensiva de lo inapropiado de tal enfoque híbrido, y continuaremos analizando en qué consiste el nuevo método galileano de su segunda fase, cuando ya ha abandonado por completo la atención al sistema de creencias aristotélico; ahí se encuentra el paso hacia la preferencia por las soluciones al trabajo sobre las creencias. Veremos en qué consiste ese paso.

Si elegí en su momento el problema de la aceleración, es porque parece punto de referencia obligado de toda la transformación, es decir, el objeto que venimos esperando que aparezca en algún instante del relato suplantando el dogma aristotélico de la proporcionalidad fuerza-velocidad en el movimiento. El paso citado hacia la segunda fase de la ciencia galileana, su pequeño-gran salto ${ }^{33}$ y la adopción de la aceleración como elemento natural al movimiento son casi identificables. De hecho la segunda nos puede ayudar a identificar al primero, y así lo hará. En tal salto hay un paso cualitativo por parte de Galileo en el plano de la metodología que merece la pena que sea destacado.

\section{Primeras tentativas: contradicciones y frenos en el De motu.}

En la sección anterior hablé del punto de vista "relativista" del que Galileo parte para señalar la causa de todo movimiento en un medio. El nuevo punto de vista era cuantitativo, y se basaba en que la diferencia de pesos de volúmenes

32 Recordemos, aquella tradición preocupada de pulir los argumentos de la Ftsica aristotélica en torno a las características fundamentales del movimiento, mediante la argumentación y la lógica (excepcionalmente desde un punto de vista matemático, que nunca supuso un obstáculo a las creencias aristotélicas). Ver apartado anterior.

33 He empleado esta expresión con la intención de hacer ver que estamos ante un proceso de cambio cientifico que se inaugura con cortos y progresivos pasos motivados por el intento de alcanzar la máxima corrección teórica en la descripción de un fenómeno. Así, lo que aparentemente adquiere el mismo significado que un caminar paso a paso, con algún pequeño salto entre uno y otro, es apreciable históricamente como el relato de un salto de gigante. Tales son las excelencias de la perspectiva histórica ( $\mathrm{y}$ también sus cegueras). 
iguales tomados de un medio y del cuerpo que en él se mueve está en el origen de la caracterización causal del movimiento del cuerpo en el medio. La dinámica del movimiento local de los cuerpos aprovecha una (aparente) "neutralización" de la ontología aristotélica en el ámbito local y se desarrolla conforme a una concepción arquimediana del movimiento. La otra idea de la diversificación del movimiento en función de la composición elemental de los cuerpos (una caracterización cualitativa aristotélica) queda fuera de lugar. La influencia de las tradiciones matemáticas que introdujimos en el apartado anterior se puede hallar, ya por vez primera, en esta refundamentación de las bases sobre las que se desplegará el resto de la investigación del De motu. Tal transformación tiene como base la hidrostática arquimediana (Solís, 1983, págs. 73-76; Wisan, 1974, págs. 134-135). Con ello nos encontramos ante el nuevo planteamiento galileano que facilitaba la matematización.

No obstante, debemos recordar que Galileo no era ajeno a un creencia fundamental: los cuerpos más pesados tienden a ocupar un espacio por debajo de los menos pesados (los ligeros en la ontología aristotélica). Esta creencia aristotélica, que adquiere sentido en una ordenación también aristotélica de la naturaleza, con las tendencias absolutas hacia los lugares naturales incluidas (cf. De caelo, IV; Barnes, 1984, págs. 502-511), inunda los escritos de aquellos que se pueden considerar menos filósofos, más preocupados de problemas prácticos, y sus huellas nos llevan de Arquímedes hasta el mismo Galileo, precisamente por el camino más ajeno a la establecida ortodoxia aristotélica. Por ejemplo, la tendencia de los cuerpos hacia el centro del universo (una creencia tan aristotélica como el propio universo en que se halla dibujada) se encuentra incluso en Arquímedes, en su tratado hidrostático Sobre los cuerpos flotantes (Vega, 1986, pág. 17). Los postulados de base de Jordano Nemorario la toman como lugar común de forma similar: "el movimiento de un peso es hacia el centro de la Tierra" ${ }^{34}$.

Más allá de Jordano, Tartaglia emprende su investigación sobre el movimiento de proyectiles sin poder desembarazarse de otra creencia aristotélica: la negación de la simultaneidad de movimientos violentos y naturales, un problema que veremos que Galileo posee en su propio De motu. Pero aún cuando supera tal distinción en los Quesiti (Koyré, 1977, págs. 103-124), Tartaglia no

34 Realmente la creencia aristotelica fundamental de Galileo no es más que una reélaboración más aséptica frente a las influencias ontológicas aristotélicas de esta misma afirmación de Jordano. 
puede librarse de la primera creencia sobre la ordenación del universo y sobre las tendencias naturales de los cuerpos.

Galileo emplea su formulación arquimediana de las causas del movimiento de los cuerpos tras prescindir de las creencias ontológicas aristotélicas, una vez que logra encontrar un terreno neutral sobre el que desarrollar un estudio matemático del movimiento. Pero ya hemos visto que no es capaz de adoptar tal nivel de abstracción, con lo que poco de él se sale de Aristóteles. Ni siquiera las consideraciones galileanas sobre los fenómenos observables que emplea en el De motu van más allá de la acotación prescrita para lo naturalmente posible dentro del sistema de creencias aristotélico.

Pero, sobre todo, debemos hablar de un elemento en particular de tal aristotelismo en el De motu ${ }^{35}$. Tal elemento muestra la tensión habida entre un modelo de estudio fisico y otro (el modelo aristotélico frente al arquimediano; sobre ello, cf. Solís, 1983, págs. 73-76; Vega, 1986, págs. 15-17). En el De motu dialogus Galileo estudia a partes iguales el movimiento natural y el forzado. El problema más útil (y más tratado) es el de la proyección hacia arriba de un cuerpo que inmediatamente después de llegar a alcanzar la altura máxima comienza a caer en un movimiento natural de caida libre. Útil porque permite definir desde un principio las condiciones teóricas básicas de los movimientos naturales y de los movimientos violentos, estudiar su conexión en la proyección y deliberar acerca de los "accidentes" que se producen en ellos. Para empezar con los elementos de contradictoriedad que muestran explícitamente la mencionada tensión, el problema nos es suficientemente fértil. La simultaneidad del movimiento violento y del natural en los inicios de la caida libre (momento que se aprovecha para incluir en él todo proceso acelerativo o decelerativo) visible en los últimos análisis del De motu (Drake \& Drabkin, 1969, págs. 355 y sigs.), choca con la distinción teórica marcada por Aristóteles. Distinción que, algo contradictoriamente, Galileo acepta en el mismo texto desde sus comienzos (Drake \& Drabkin, 19699, págs. 332-338; pero véase su aparición reiterada más allá de estas páginas, pág.e., págs. 355 y sigs.).

Comencemos por la pregunta de Domenico de si existe un intervalo de reposo en la proyección hacia arriba de un cuerpo, justo en el momento en que

35 Aunque, por supuesto, en este trabajo no se pretende ofrecer un indice exhaustivo de las creencias aristotélicas de Galileo. Solo aludimos a aquellas que atafien al problema del que nos ocupamos. 
deja de ascender y comienza a caer. Galileo responde a esto que no es posible. (Esta cuestión del reposo o no, en el punto de inflexión del movimiento, es sumamente útil dada nuestra intención de apreciar los elementos de contradictoriedad que pueden verse en el De motu, a partir de la distinción entre movimientos natural y violento frente al problema de la aceleración, por lo que entraremos en detalle en ella.) Galileo introduce el reposo como un estado de transcurso temporal pero de estancamiento espacial, allá donde el movimiento implica continuidad de avance en ambas dimensiones, i.e., el tiempo y el espacio ${ }^{36}$. La prueba de que no es posible un instante de reposo en dicho punto de inflexión se divide en dos partes. Una se refiere a la demostración de que la fuerza impulsora de la proyección hacia arriba va decreciendo conforme el cuerpo sube. Estudiemos la figura siguiente:

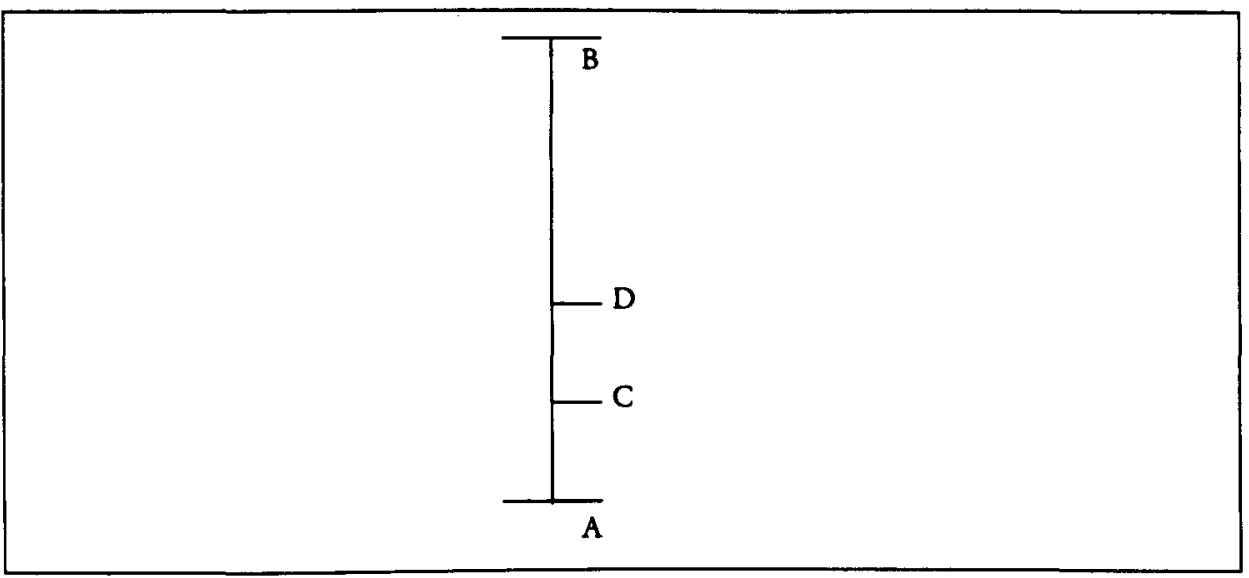

Fig. $1^{37}$

Si en una trayectoria ascendente $\mathrm{AB}$ (ver fig. I) tomamos dos puntos intermedios $C$ y $D$, la fuerza que se imprime al cuerpo (y que por ser mayor que su

36 Cf. DraKe \& DraBKIN, 1969, págs. 355-357. En cuanto a esta apreciación del movimiento y el reposo como avances en el tiempo y no en el espacio, puede verse su origen en Estratón y, más tarde, en Boecio, por más que, en Aristóteles, movimiento y reposo eran formas del ser cualitativamente distintas. Para ello, cf. SAMBURSKY, 1990, págs. 25-30. Con todo no veo relación directa de aquellos con Galileo. Aquf he empleado la versión expuesta por Sambursky como una artimafia explicativa.

37 El mismo esquema aparece en la pág. 356 de la edición de DRAKE \& DRABKIN, 1969. 
peso permite el impulso hacia arriba) va en disminución a lo largo del recorrido. Es decir, esa fuerza se agota. Por tanto, por C y por D no puede pasar el cuerpo con un impulso motivado por una misma fuerza (o mayor en el punto más alto que en el más bajo). Porque incluso si sólo fuera igual, en tal caso la trayectoria $\mathrm{CB}$, recorrible desde $\mathrm{C}$ hasta $\mathrm{B}$ por la fuerza impulsora, habría de ser la misma que la DB. Pero esto no es posible, porque si fuera así el cuerpo ascendería más allá de B. En ello se basa la primera parte de la prueba de Galileo ${ }^{38}$.

Así, en segundo lugar (la otra parte de esa prueba) y respondiendo a Domenico, es imposible, por la disminución constante de la fuerza impresa que exista un intervalo de tiempo, por pequeño que sea, en que la fuerza se iguale al peso. Porque ello equivaldría a decir que hay dos instantes ${ }^{39}$ de ese intervalo temporal en que la fuerza, igualada al peso, mantendría al cuerpo en reposo hasta el final del momento de tiempo total. Pero en el instante siguiente (dentro del mismo intervalo) poseería el mismo estado de equilibrio que antes (i.e., la fuerza impulsora se mantendría en su grado de empuje primitivo), suficiente como para mantener en reposo el cuerpo durante un instante más, como el de antes. Al final de este último aún estaría en reposo, en las mismas condiciones de fuerza, con lo cual nada impediría un estado de reposo indefinido, lo cual es absurdo. (Drake \& Drabkin, 1969, pág. 357) Con ello queda rechazado el estado de reposo en el punto de inflexión. Quedémonos con ello.

Para Galileo, los movimientos natural y violento son contiguos, aunque no son nunca continuos, tal continuidad era rechazada de pleno por Aristóteles. Tal rechazo no es de extrañar: la continuidad no tiene lugar allá donde distinguimos entre movimiento natural y forzado, pues ésta implica prosecución de un mismo tipo de estado de una misma naturaleza. Pero tampoco tiene sentido introducir un intervalo de reposo entre ambos, puesto que el reposo es, en

38 O, dicho de otro modo, en caso de pasar el cuerpo por ambos puntos intermedios con una fuerza idéntica, y por los mismos motivos argumentados por Galileo, la trayectoria DB estaría falsamente representada con respecto a $\mathrm{CB}$, y esa representación sería sólo idéntica en caso de que CB y DB fueran iguales, con lo cual, el único caso posible es aquel en el que la fuerza que pasa por cada punto disminuye a medida que nos aproximamos a la cima (en el caso de la proyección hacia arriba).

39 Dice Galileo en una nota luego no incorporada al texto que «dos instantes de tiempo, por lo que respecta a la divisibilidad o a la indivisibilidad, son lo mismo que un instante." Sefrala DrabKIn (DRAKE \& DrABKIN, 1969, pág. 362, nota 47) que más tarde borró tal anotación del De motu. 
la ontología aristotélica, también cualitativamente diferente del movimiento. Sólo la contigüidad implica que hay dos tipos de movimiento intrinsecamente distintos (causalmente distintos, en este caso) que se suceden uno al otro. Tal solución de inmediatez es necesaria de cara a la caracterización aristotélica del movimiento y adecuada a la citada consideración sobre el reposo en el movimiento local (una consideración plenamente "galileana" en su presentación). El proceso de contigüidad de movimientos natural y violento parece adecuado a una explicación del movimiento de proyección hacia arriba (y su caída libre subsiguiente), sobre las bases (híbridas) del De motu. En resumen, en la contigüidad queda claro que estamos hablando de formas necesariamente diferentes y no simultaneas de movimiento: el natural y el forzado, y que su contigüidad (que no su continuidad, por supuesto) no está marcada por intervalo de reposo alguno. Tal caracterización es aparentemente satisfactoria (según el canon del De motu) como explicación de esa fase de inflexión en el movimiento tratado.

Pero, llegado el final del De motu dialogus la explicación de algo «accidental” como la aceleración parece chocar con este elemento de distinción de movimientos. En efecto: la aceleración en el movimiento de caída es una fase de ésta, que se produce por la disminución progresiva de la fuerza impresa desde un estadio de igualdad al peso desde el punto de cese del ascenso, en el que el cuerpo comienza a caer. La fuerza continúa disminuyendo a partir de ahí y, paralelamente, la tendencia natural del peso a caer trae el cuerpo hacia el centro de la Tierra generando un proceso acelerativo ${ }^{40}$. Pero esto implica que, durante el proceso de aceleración, en el que la fuerza impresa disminuye y la velocidad aumenta hasta que la primera desaparece y ésta se estabiliza, hay simultaneidad de un movimiento forzado (por la actuación de la fuerza impresa) y uno natural (el motivado por la tendencia natural hacia el centro de la tierra): Simultaneidad, no contigüidad ${ }^{41}$. Esto plantea un problema diff́cil de resolver;

40 Sobre el origen tradicional de esta explicación en Hiparco, Juan Filopón y Francisco de Marchia, cf. SAMBURSKY, 1990, págs. 83-92 y DRAKE, 1989, págs. 30-31.

41 Pero ambas apoyan la negación del reposo en el punto de inflexión. Esta negación que, como hemos podido ver, Galileo argumenta convenientemente, requiere la disminución progresiva de la fuerza, a la par que, en el esquema de contigüidad galileano (de reminiscencias aristotélicas) es igualmente clave. El problema que surge con ello es la convivencia de elementos incompatibles entre sí: la disminución progresiva de la fuerza no es compatible con la contiguidad del movimiento ni - lo que es más importante- con la dicotomía movimiento natural/violento que la sustenta, pese a que en ambos casos la negación del reposo no sólo es aceptable, sino que es casi un requisito. Desde aqui hay via libre sólo en una dirección: mientras se mantenga la 
un problema que surge tras la interpretación matemática realizada sobre creencias aristotélicas. La explicación de la aceleración entra, pues, en conflicto con la caracterización aristotélica del movimiento aceptada en un principio por Galileo; más aún, fuerza una contradicción interna en la argumentación general del De motu.

En efecto, si aceptamos la simultaneidad a que nos conduce la explicación de la aceleración como fenómeno accidental, no podremos aceptar la distinción neta entre movimientos que nos fuerza a señalar que no son ni siquiera continuos, sino contígüos, y viceversa, la aceptación de la diferenciación neta entre movimientos y su no simultaneidad es un obstáculo contra una explicación de la aceleración en los términos pretendidos. Dado que ambas afirmaciones se presentan en el mismo texto, estamos ante una fuerte contradicción interna.

La no-simultaneidad de los movimientos natural y forzado y la explicación de la aceleración como fenómeno accidental (una limitación prescrita desde el sistema de creencias aristotélico), conducen, por tanto, a la inconsistencia interna de los argumentos galileanos. El proyecto de Galileo, una explicación dinámica según un modelo arquimediano del movimiento local, se encuentra "frenada" por su plegamiento al sistema de creencias aristotélico, y su perseverancia en tal proyecto hibrido genera inconsistencias o contradicciones como la que acabamos de examinar. Galileo no es, ni mucho menos, consecuente con las implicaciones de su propia interpretación, en el De motu. Esto viene dado por su fidelidad al sistema de creencias aristotélico. Sus propios argumentos acerca de la aceleración (accidental) no alcanzan a tomar el cuerpo que deben para tornarse en soluciones a todas luces aceptables y es, precisamente, por tal dependencia.

mencionada dicotomía no es previsible poder encontrar una explicación de la aceleración (ni accidental ni natural) en términos de la actuación de la fuerza impresa, único modo de dar cuenta de ella (y, en general, de todo movimiento violento) con cierto éxito hasta el momento. Esa creencia obstaculiza la explicación efectiva de la aceleración en los términos de accidentalidad. Pero, por otro lado, y según la explicación hiparquiano-galileana, si la fuerza impresa actúa en todo movimiento natural como el da calda libre, jen qué sentido podemos tratar la aceleración como un evento accidental? De hecho, sólo una creencia impide el paso libre a la aceptación de una aceleración natural del movimiento bajo la acción de una fuerza constante (i.e., el rechazo del carácter «accidental» de la aceleración): la sólida creencia en la proporcionalidad aristotélica fuerza-velocidad. Tirar abajo este sólido edificio requiere una actitud metodológica dispar (como la que veremos en el próximo subapartado) y resultados experimentales como los que alcanzará Galileo años después. Pronto hablaremos de ello. 
Junto a este caso en el De motu dialogus, podemos observar otro, en el ensayo del De motu, en el que las creencias aristotélicas, no apartadas del escenario en que se tratan problemas del movimiento local, actúan de freno al estudio del problema de la aceleración. Es decir, no se trata de que tal dependencia pueda generar impedimentos e inconsistencias en el proceso explicativo; esa dependencia impide la orientación del estudio hacia un problema determinado, aunque podamos considerar externamente que así hubiera podido ser. En el ensayo del De motu (Opere, I, págs. 251-366) nos encontramos presumiblemente ante el problema de la aceleración, pero éste no es tratado como elemento teórico participante, sino como accidente que afecta a la apreciación observacional de los resultados teóricos. Galileo acepta plenamente uno de los postulados básicos del sistema de creencias aristotélico, en este caso el de la velocidad constante a fuerza también constante. Winifred Wisan lo analiza esquemáticamente, pues en él se encuentran algunas de las claves de la posterior evolución conceptual y metodológica de Galileo (Wisan, 1974, págs. 151153). Su análisis del movimiento se extiende en este texto (más extenso que el diálogo) a los problemas de caŕda por planos de diferente inclinación, al margen de los tratamientos realizados en el diálogo. De manera semejante al principio arquimediano ya conocido, y aceptando el postulado básico de Jordano 42, Galileo seńala que la fuerza de descenso de un cuerpo por un plano inclinado será la misma que la necesaria para mantener a ese mismo cuerpo en reposo en tal plano. En esta fase del trabajo encontramos la influencia decisiva de Jordano Nemorario y de Tartaglia. Galileo emplea el principio de la balanza, estudiado en tal tradición, y cuyo estudio nos retrotrae a las Cuestiones de Mecánica pseudo-aristotélicas ${ }^{43}$, y de ahí extrae la mencionada fuerza de descenso. El opera - al contrario que ambos autores citados- partiendo desde el principio para llegar al concepto empleado en la caracterización del equilibrio. Pero dado que asume que el movimiento de un cuerpo en el cuadrante inferior de un círculo (lugar donde se estudia el problema de la balanza desde

42 Un cuerpo pesado se mueve hacia abajo con tanta fuerza como la que es necesaria para levantarlo, o con la misma fuerza con la que se resiste a ser elevado. Cf. WISAN, 1974, pág. 150

43 No hay una influencia de las Cuestiones de Mecdnica en la ciencia medieval del peso, la cual se inspira en la Fúsica de ARISTÓTELES para buscar sus principios (ver apartado anterior). En lo que sí se parecen es en el objeto de estudio. Las Cuestiones son una fuente de casos a estudiar y, por qué no, un clásico del campo (en el sentido kuhniano-KuHN, 1980-). En el siglo XVI se emplé a Arquímedes como medio de crítica a tal fuente (WISAN, 1974, pág. 132). Con todo, debe ser citada. 
las citadas Cuestiones) se puede identificar con el movimiento por el plano tangente a ese círculo en ese punto, el enfoque es el adecuado para encontrar la mencionada fuerza de descenso (por tal punto). La prueba es plenamente propia, pero hay una idea de base que impide el libre acceso de la aceleracion al campo del estudio del movimiento como objetivo principal: toda fuerza de accion constante provoca un movimiento a velocidad constante ${ }^{44}$. Galileo obtiene finalmente que la fuerza de descenso depende de la oblicuidad del plano; según la oblicuidad así será la velocidad que tome en el descenso por el plano: las velocidades a lo largo de planos de distinta inclinación pero de idéntica altura vertical, son inversamente como las longitudes de los planos (Wisan, 1974, págs. 152153). La aceleración es una perturbación fenoménica que impide la libre observación del (verdaderamente importante) resultado teórico ${ }^{45}$.

Como muestra representativa del tipo de "soluciones" a los problemas del movimiento local que se obtienen desde el enfoque híbrido del De motu creo que lo presentado hasta aquí es suficiente. Por así decirlo, pese al empleo del planteamiento y las técnicas matemáticas de las tradiciones de Arquímedes, la ciencia medieval del peso y la de Tartaglia, la raigambre creencial es plenamente aristotélica. Esto provoca callejones sin salida como los citados.

La radicalización de un método y la búsqueda de soluciones: la consumación del salto

El pequeño-gran salto que buscamos (es decir, la aceptación de la aceleración que se produce por otra previa más profunda, la del planteamiento matemático y experimental que hace oídos sordos a muchas de las creencias aristotélicas de base), se encuentra metodológicamente más allá del De motu y cronológicamente al final del siglo, ya entrando en el XVII. No obstante esas creencias dejarán su huella: Galileo no dejará de ser un matemático "más físico".

44 Véase la nota 41.

45 Galileo, conforme ocurre en su época (de ello hemos hablaremos más tarde) estaría afectado, en un principio, por la consideración de que es el resultado térico, y no la observación, lo que ha de tenerse en cuenta en el estudio de la naturaleza. Como sefiala Wisan, "la nueva ciencia del movimiento comienza como una ciencia puramente racional ocupada con el movimiento 'natural' o intrínseco de un cuerpo, y sin tener en cuenta la realidad fisica." (WISAN, 1974, pág. 153). 
Nuestra última parte del relato nos acerca al Galileo más conocido, el de sus años de madurez, al que se han atribuido los mayores logros para la ciencia del futuro. Es el Galileo plenamente entregado a las nuevas técnicas matemáticas y al tratamiento experimental. Pero la manera en que combina ciertos métodos arquimedianos con la experimentación; la forma en que pide seguridad en los principios desde los que realiza sus razonamientos ulteriores y sus demostraciones; la pasión metódica por asegurarse los pasos tras de sí y en pro del futuro, de tal manera que haya proximidad a lo físico y observable en ambos flancos, nos habla de un hombre convencido por las nuevas técnicas y métodos. No obstante, el "estilo matemáticon" ${ }^{46}$ que Galileo despliega no le libra de su pasión por la causa y por la utilidad de la matemática en el estudio de la realidad fisica. Ese "estilo matemático" puede considerarse herencia de su seguimiento de los estudios italianos de problemas prácticos de mecánica. Pero su búsqueda de las causas y el desarrollo de una metodologia que busca incluirlas en el estudio del movimiento, corresponde más a su formación como filósofo natural dentro de la corriente académica más tradicional (la filosofía del movimiento).

En el espacio de una década, con sucesivos cambios de vivienda y el paso de la condición de estudiante a la de profesor privado, Galileo redactó el $D e^{\circ}$ motu antiquiora. Según Drake es la incorrección de algunos teoremas sobre la

46 La afirmación de "estilo matemáticow definida por Cohen aparece en The Newtonian Revolution (Cambridge, Cambridge University Press, 1980), y la he obtenido indirectamente de la referencia que hace a ello Carlos Solis en su Solis, 1983, pág. 86. Ahí remarca éste último que el "estilo matemático" es un estilo kacabado en el caso de Newton, aunque ya presente en Galileo, consistente en formular un sistema matemático ideal donde, a partir de condiciones de las fuerzas y/o movimientos supuestos, se deducen con libertad matemática las consecuencias, a fin de comparar en un momento posterior esos teoremas con las observaciones, viendo así en qué medida el constructo original constiruye un análogo del sistema fisico real e introduciendo las modificaciones y complicaciones pertinentes para hacerlo más precison (SOLIs, 1983, ibid.). Sin duda hay una gran diferencia entre un estudio dinámico causal como el que predica Aristóteles y un estudio de las caracteristicas del movimiento, más descriptivo que explicativo y causalista. Prescindir de las causas es el precio que Galileo tiene que pagar para conseguir un esquema válido de soluciones a los problemas del movimiento, uno de los cuales es la descripción de la aceleración en caída libre (una vez, claro está, que se contempla la aceleración como algo intrínseco al movimiento bajo la acción de una fuerza constante). Todo lo dicho no implica que Galileo deseara quedarse ahi. Más bien parece haber sido consciente de una necesidad de reconstrucción de las creencias: una refundamentación de la ciencia del movimiento. (Cf. Souls, 1983, págs. 84-86, y en general todo el texto para rastrear desde un principio esta idea. En é aparecen explicadas ciertas fases del trabajo de Galileo sobre las que no tendremos oportunidad de entrar, pero que complementan lo que aqui estudiaremos). 
velocidad de los cuerpos en planos inclinados lo que avisa a Galileo de que el De motu debería ser corregido. La regla empleada para el equilibrio en planos inclinados difería de la adoptada por Guidobaldo del Monte y por Cardano y, además (e incluso después de revisarla) no proporcionaba un test experimental de examen. A la larga, señala Drake, Galileo abandonaría su creencia en la aceleración como un evento accidental (Drake \& Drabkin, 1969, págs. 5960). Como señala Carlos Solís (Solís, 1983, págs. 76-77), el estudio matemático de la teoría de las máquinas en Le mecaniche, donde ya emplea el concepto de "momento" (cf. Solís, 1983, ibid.) llevará a un planteamiento en el que "se hará insoslayable el problema de la aceleración" (Solis, 1983, ibid. ${ }^{47}$ ). La aceleración como algo natural aparece en algún momento entre la última década del siglo XVI y 1603, cuando inicia sus experimentos con planos inclinados y con péndulos (Drake, 1989, págs. 35-49), de los que extraerá la base empírica necesaria para desarrollar la ley de caída de los cuerpos (en la que ya se trata la aceleración como elemento propio del movimiento), comunicada por vez primera a Sarpi en carta en 1604 (Opere, X, págs. 115-116) y descrita más tarde en los Discorsi.

Pero a mi parecer todo esto es como la piel sin los huesos: nada sostiene el proceso de transformación que conduce a la aceptación de la aceleración como algo natural. Todo ello corresponde a la radicalizacion de una metodología originada en la profundización de Galileo en el tratamiento de problemas físicos mediante técnicas matemáticas, que sigue el tono de la parte más alternativa al aristotelismo - la metodológica- de las que componen la interpretación iniciada en el De motu. Galileo no "da por sentado" ${ }^{48}$ todo lo presentado en el sistema de creencias aristotélico como «descripción de la realidad" y busca nuevos principios directamente de los fenómenos. La física, así fundamentada,

47 Véase este artículo (Souts, 1983) para comprender en qué consiste tal planteamiento. Aquil es suficiente con saber que en tal texto hay un paso intermedio hacia la aceptación galileana de la aceleración como problema primordial a tratar teóricamente. Véase también Le mecaniche en Opere, II, págs. 147-191, incluyendo la presentación de A. Favaro.

48 Un breve inciso: es ese "dar por sentado" algo, lo que dota a la educación científica en el seno de un sistema de creencias para establecer un dominio rígido sobre el terreno de alo posiblen. (Sobre ello, cf. KuHN, 1980). Qué es y qué no es posible está comprendido en lo que se "da por sentadow. Cuando Galileo se salta a la torera este límite está dando un paso a la vez dificil e irreversible, de consecuencias decisivas para el desarrollo ulterior de la mecánica. Esto se produce en su radicalización. La generación de una metodología renovada que nos conduzca a nuevos principios que, en cierto momento, puedan llegar a "darse por sentados", parece un paso plenamente coherente, desde esta perspectiva. 
ayudaría a que la matemática no fuera el juego hipotético de unos cuantos especuladores.

El vocabulario es plenamente matemático $\mathrm{y}$, como en toda teoría matemática, Galileo debía partir de un grupo de Definiciones básicas. Como toda Definición se encuentra sometida a un cierto grado de arbitrariedad y a la constricción de las teorías sobre el mundo (y su generación de estados de «sentido común", como vimos) la pretensión galileana nos puede parecer demasiado optimista. Pero Galileo trata de evitar las dudas mediante un uso del experimento en la cadena argumentativa (i.e., en la prueba de las soluciones) bastante original. Veámoslo.

La garantía de éxito en el trabajo de la matemática en la física radica en que las Definiciones de las cuales se derivan las proposiciones posean un apoyo empírico suficiente, de tal manera que todo proceso de deducción formal posterior se asiente en principios apoyados directamente en los fenómenos ${ }^{49}$.

(...) las Definiciones desempeñan en Galileo la función básica de garantizar la relevancia empírica de las proposiciones derivadas (puesto que se emplean como proposiciones primitivas o axiomas). Mientras que las reglas de deducción demuestran formalmente los teoremas, la definición correcta (es decir, esencial) asegura que los axiomas, al expresar la verdadera naturaleza del fenómeno, serán capaces de transmitir la verdad al resto de las proposiciones deducidas que constituyen la ciencia del movimiento. (C. Solfs, nota 5, tercera jornada de los Discorsi, ed. esp., Galileo, 1638, pág. 267).

Podemos encontrar una afirmación tajante del propio Galileo con respecto al problema que aquí nos trae: la aceleración del movimiento. Básicamente, si vamos a estudiar tal fenómeno en profundidad, mejor será que aseguremos los cimientos antes de construir cualquier edificio encima:

49 El primer paso en el De motu era obtener ciertos principios que proporcionasen la posibilidad de matematización ulterior. La base empírica sobre la que se asentaban era bastante más exigua que la que veremos a partir de entonces. Más bien estábamos ante la cuantificación de conceptos hasta entonces sólo incluidos dentro de una discusión cualitativa. La separación del plano de discusión respecto de la realidad fenoménica es mucho mayor; prácticamente, el De motu se despliega en un plano más racionalista que empirista por este motivo. A este respecto, el Galileo post-pisano difiere bastante del autor del De motu. 
Ante todo, es necesario investigar y explicar la definición que corresponde con exactitud al movimiente acelerado que nos brinda la naturaleza. En efecto, aunque sea lícito imaginar arbitrariamente ciertas formas de movimiento e investigar las propiedades que de ellas se derivan (...), no obstante, y desde el momento que la naturaleza se sirve de una determinada forma de aceleración, en los cuerpos pesados en caida libre, hemos decidido estudiar sus propiedades, haciendo que la definición que hemos de dar acerca del movimiento acelerado en cuestión corresponda a la esencia del movimiento naturalmente acelerado. (Galileo, 1638, pág. 275. Subrayado mío).

La única manera de salvaguardar la verdad de toda aquella proposición derivada consiste en asegurar la verdad de nuestros axiomas mediante Definiciones correctas de los fenómenos. Esto nos lo proporciona el examen minucioso de la naturaleza. Pero, ¿cómo se lleva a cabo ese examen minucioso?; ¡‘ómo sabemos cuándo estamos ante una "Definición correcta de los fenómenos"?

Hagamos un inciso: podemos decir en contra de esta línea de argumentación que estoy siguiendo que tal procedimiento galileano no deja de tener un cierto aroma aristotélico - ojeense los Analiticos Posteriores, p.e. En el fondo la inspección precisa de los fenómenos y el ansia de encontrar "esencias" no deja de serlo. Pero es que en el fondo es esa intención el último resquicio vivo del aristotelismo que se mantiene en todo su fragor, mientras que el resto de creencias se han ido silenciando poco a poco ${ }^{50}$. La búsqueda de Definiciones precisas de los fenómenos mediante un escrupuloso escrutinio experimental se corresponde bien con la elección del físico de una serie de técnicas de resolución matemáticas. No podemos pedirle que cese en su condición aceptada de físico y se transforme en un matemático especulativo. La transformación en lo que hemos denominado «inclinación hacia las soluciones" emplea esa combinación medida de matemática y experimentación.

Esa es la forma en que Galileo expondrá las soluciones a los problemas del movimiento local en sus Discorsi. Pero tratemos de responder a las preguntas arriba formuladas: ¿en qué consiste el respaldo empírico de sus teorías hasta el extremo en que Galileo pretende que están respaldadas?

50 Si seguimos la caracterización actual de Aristóteles dentro de la visión que nos proporciona Jonathan Barnes, es precisamente esa investigación precisa y directa de la realidad fenoménica la que es «más aristotélica», y no el cúmulo de dogmas sobre los que se asientan las discusiones escolásticas. Cf. BARNES, 1987. 
Como ya hemos dicho, las pruebas no parten de la arbitrariedad, aunque estemos ante una forma de razonamiento muy similar al razonamiento ex suppositione. William Wallace (Wallace, 1984, págs. 338-349) se ha ocupado de investigar estos pasos del método, al igual que Winifred Wisan (Wisan, 1974). De ambos podemos extraer lo siguiente. Galileo se apoyó en una técnica desarrollada por Arquímedes (Wallace, 1984, pág. 343), algo readaptada a su concepción del método. La técnica de Galileo implicaba justificar las suposiciones en la resolución de problemas dinámicos, empleando el obligado razonamiento causal junto a técnicas experimentales ${ }^{51}$. De esta forma justificaba las Definiciones de partida mediante los resultados experimentales integrados en un escrupuloso proceso de análisis. Esto implicaría un refinamiento del método de análisis o resolución para conseguir demostrar la verdad de las suposiciones.

Wisan opina que Galileo no debió emplear el método de análisis para encontrar los principios válidos de cara al posterior proceso de demostración, sino, precisamente, para encontrar las pruebas adecuadas a argumentos principalmente asentados en las apreciaciones sensibles inmediatas ${ }^{52}$ (Wisan, 1974, págs. 117-118). Así, el empleo del experimento implicaría encontrar una justificación absoluta y cuantificada como apoyo de las suposiciones de partida. Galileo lo manifiesta asi en una parte del Diálogo sobre los dos máximos sistemas del mundo ptolemaico y copernicano (Galileo, 1632, pág. 47; citado por Wisan, 1974, ibid.):

SALVIATI: El que vos enunciais es el método con el que (Aristóteles) escribió su doctrina, pero ya no creo que sea el que utilizó para la investigación de ésta, porque estoy seguro de que primero procuró asegurarse cuanto

51 El uso del experimento no era algo demasiado extendido entre los matemáticos del XVI. Simon Stevin y Jan de Groot comprobaron la afirmación de Benedetti (y de paso la ulterior de Galileo) en 1586 sobre la caída de cuerpos de igual materia pero distinto peso a igual velocidad en un mismo medio. Pero Stevin se propuso este experimento por su condición de ingeniero preocupado en asuntos prácticos tanto como en los teóricos. A Benedetti no le pareció nunca un paso necesario. Nada empírico podía superar en seguridad de resultados a la prueba matemática (cf. DraKE, 1989, págs. 28-29). El empleo de Galileo del experimento es plenamente diferente (y, por qué no decirlo, muy original), pues se integra en el proceso de análisis en que se justifican los principios sobre los que se apoya todo proceso demostrativo ulterior. Además su papel es hacer desaparecer del proceso todo resquicio de circularidad mediante el desarrollo de experimentos diferentes para el proceso justificativo, de los realizados para efectuar confirmaciones empíricas. CF. WALLACE, 1984, págs. 338-349.

52 Véase 'en la experiencia', no 'en el experimento'. 
fuera posible de las conclusiones mediante los sentidos, las experiencias y las observaciones, y que después trató de buscar los medios para poder demostrarlas, porque así se hace usualmente en las ciencias demostrativas. Eso sucede porque, cuando la conclusión es verdadera, sirviéndose del método resolutivo, fácilmente se encuentra alguna proposición ya demostrada, o se llega a algún principio conocido por sí mismo. Pero si la conclusión es falsa, se puede proceder al infinito sin encontrar nunca una verdad conocida, cuando no se encuentra algo imposible o algún absurdo evidente.

Así pues, si quería introducir la aceleración como elemento clave integrado en todo estudio sobre el movimiento, Galileo debería ser capaz de hacer que las Definiciones que hablaran de dicho elemento encontrarán suficiente soporte empírico. Para ello debía poder obtenerse como parte fundamental del movimiento en el proceso de resolución o análisis. De hecho así fue. En los experimentos con planos inclinados la aceleración aparece como uno de los elementos naturales del movimiento, tal y como pensaba que debía estar integrado. De hecho parece haber estado muy satisfecho de los primeros resultados, cuando se puso de manifiesto que en intervalos de tiempo sucesivos e iguales, los espacios de caida por el plano se incrementaban según la proporción marcada por la sucesión de los números impares, 1, 3, 5, 7, etc. (Drake, 1989, pág. 37.) Había un incremento constante de velocidad en el tiempo. Galileo inicia una larga carrera en la deducción correcta de la ley de caida de los cuerpos (cf. Solis, 1983, págs.78-80), más tarde ofrecida en los Discorsi. El primer resultado experimental le permitió realizar otros posteriores tanto sobre la caída de los cuerpos como sobre las oscilaciones pendulares (que fueron puestas en relación, con lo cual se extrajo la ley del péndulo y de ahí la ley de caida de los cuerpos; Drake, 1989 53), todo lo cual confirmó las presunciones galileanas acerca de la existencia, como parte del movimiento, de un proceso de aceleración gradual.

53 La teorfa de la proporcionalidad de magnitudes matemáticamente continuas de Euclides (Libro $\mathrm{V}$ de los Elementos), a la que hicimos referencia antes, entra a formar parte como elemento matemático decisivo, en estos pasos del análisis galileano del movimiento. La teorfa de la proporcionalidad permite detectar influencias causales participantes cuando éstas se muestran contrarias a la detección experimental. Por las características de tal teoría (véase el segundo subapartado de la sección anterior y Vega, 1986, págs. 25-27), esta es aplicable a magnitudes intensivas y extensivas. Así lo hizo Galileo al aplicarla a la comparativa entre oscilaciones pendulares y flujo de granos de fluido líquido (medidor indirecto de tiempos), lo que le permitió hallar la ley del péndulo. Como a partir de ello desarrolló la correcta ley de caida, la participación de este elemento matemático en Galileo (que obtuvo gracias a Tartaglia y su traducción italiana de Euclides, en un entorno no académico) fue decisiva. Cf. Drake, 1989. 
La búsqueda misma de sistematización de la aceleración (ahora natural, por supuesto) como elemento participante en todo estudio sobre el movimiento a través del nuevo método, ilustra e incluso se identifica con el pequeño-gran salto del que comenzamos a hablar y que venlamos buscando en una imagen comprehensiva plena. La apreciación de la aceleración es una apreciación fisica, que hubiera podido incluirse en un entorno de filosofía natural de muy diversas maneras. Lo importante es que Galileo eligió incluirla en un estudio matemático de los problemas físicos del movimiento tras elegir dicho estudio como el apropiado a ese fin. Si la aceleración chocaba de lleno con los postulados creenciales principales del aristotelismo era algo que en su momento dejó de tener importancia. Desde ese momento se produjo una transformación de gran trascendencia en la ciencia galileana: se eligió el completo desarrollo de las soluciones a problemas específicos en los que la aceleración natural del movimiento ocupaba un papel primordial, en detrimento de la atención a las creencias aristotélicas de base. Si algo en los fundamentos que conducían a las soluciones no se plegaba bien a las creencias aristotélicas, el problema era menor. Algún día habría tiempo para refundamentar toda la filosofia natural contemplando los nuevos elementos aportados por la vía de las soluciones.

Ese es el pequefio-gran salto: el pago del precio del olvido de las creencias con el objetivo de obtener soluciones correctas a problemas acuciantes; la perseverancia en, y la radicalización de, un método que ha puesto de manifiesto dichos problemas y que parece ser capaz de proveernos de las mencionadas soluciones. El problema es, en este caso histórico particular, el de la aceleración en el movimiento. La vía de las soluciones proviene de una serie de tradiciones caracterizadas por su atención a la resolución de problemas teóricos que no son exactamente los problemas fundamentales de la filosoffa natural, lugar de residencia oficial de las creencias. Y sí: hay creencias aristotélicas en esas tradiciones (en muchos de sus fundamentos). Pero lo que aportan a Galileo es, precisamente, prescindir de discutirlas. Conocerlas supuso un cambio radical para Galileo. Los cambios metodológico y conceptual fundamentales que afectarían a la ciencia del siglo XVII, por lo menos aquellos que la afectaron desde la ciencia de Galileo, poseen un origen claro en tales tradiciones de la ciencia italiana. Pero tales cambios deben también mucho a un planteamiento original galileano que nace de sus peculiares circunstancias educacionales y personales. Un conocimiento y un desarrollo propio que actuarían, ambos, como una de las causas de la Revolución Científica que ahora comienza. 


\section{Conclusión}

Con la elección de la opción que hemos denominado radicalización (la opción por las soluciones) Galileo nos muestra el producto de una decisión. Dejando al margen la causa exacta de la misma (como dije que haría), lo que tal elección denota es el deseo de resolver un problema que se plantea no antes de un cambio de teoria, como correspondería a un proceso de cambio por anomalía (Kuhn, 1962, págs. 52-65) y tampoco, por supuesto, después del cambio teórico. Estamos ante el deseo de resolución de un problema descubierto en el curso de una alteración sin vistas a una sustitución plena de un sistema de creencias por otro.

La elección no es obvia, pues va contra un comportamiento previsible situado ante las opciones en que Galileo parece encontrarse. Lo hemos visto como un aristotélico versado también en tratamientos matemáticos arquimedianos y hemos mencionado cómo las creencias aristotelicas condicionan el aspecto final del De motu. En tales condiciones, puesto que es el sistema de creencias establecido (un conjunto holista) el que define la actitud cientifica (la postura del cientifico) de cara al tratamiento y la resolución de problemas, la radicalización como opción elegida va contra toda previsión posible. El proceso de interpretación era lo suficientemente (metodológicamente) ajeno a la ortodoxia de las creencias aristotélicas como para que un «aristotélico» considerase el fallo (visible en el De motu) como una premonición de lo erroneo del nuevo planteamiento conjunto.

El primero de los apartados de este artículo diferenciaba las creencias galileanas de la filosofia natural de Aristóteles. El sistema de creencias aristotélico es, según esa diferenciación, algo similar a una tradición en la que está educado Galileo. Pero dado que está educado en ésta como en otras, las creencias científicas (propias, individuales) de Galileo constituyen un grupo híbrido diferente del esquema homogéneo del aristotelismo (o de los aristotelismos, como los vimos en el segundo subapartado de la primera sección). Un grupo híbrido con más de un planteamiento metodológico posible y con sus correspondientes grupos de criterios de validez.

(Haciendo un inciso, es previsible que Galileo comenzara por ordenar su nuevo espacio de creencias personal mediante una reelaboración metodológica -como la que hemos visto- para, de ese modo, tratar de aclarar los fundamentos de su nuevo esquema conceptual.) 
Si tomamos las creencias de Galileo como tal grupo híbrido, en tales condiciones educativas, ni su comportamiento parece ir tan a contracorriente, $\mathrm{ni}$ su investigación iniciada en el De motu se convierte en algo extraordinario en las condiciones en que la lleva a cabo. La convivencia geográfica y cultural de tradiciones de métodos científicos complementarios (que desde una perspectiva interna a cada contexto comunitario pueden constituir perspectivas encontradas), aplicables en ocasiones a problemas comunes (aunque no idénticamente enunciados), constituye la condición de posibilidad para una educación mixta como la de Galileo y, por lo tanto, la condición necesaria para llevar a cabo la investigación en los términos vistos y para la toma de las decisiones que hemos venido estudiando.

Este origen de un cambio científico es menos llamativo que el citado de la anomalía, pero no es por ello menos efectivo. Precisamente este caso histórico logra descubrirnos que cada proceso de cambio cientifico requiere un estudio particularizado. El cambio científico se sumerge en las oscuras y frías aguas de un mar de conexiones causales, que hay que desentranar, y de pasos conectados cronológicamente ordenados, que deben ser establecidos según su correcto orden. Expresándolo llanamente, cada proceso de cambio depende de unas condiciones particulares y está ordenado y causalmente conectado de una forma específica e individualizable (al margen de toda ulterior generalización posible). Un esquema teórico que se precie no puede establecer límites a tal variedad; más bien, si pretende ser útil, ha de prestarse a ella y depender en gran medida de la variedad casústica.

Para finalizar, como ya mencionamos, este estudio permanece incompleto: faltan las causas exactas de la decisión galileana, su propio testimonio al respecto de las decisiones tomadas. De contar con ello nos acercaríamos quizá del todo a la acción de las condiciones citadas en el comportamiento galileano visible. Las teorizaciones habidas entorno a los factores participantes en los procesos de cambio científico están realmente necesitadas de casos claros semejantes.

\section{Referencias}

Barnes, J. (ed.) (1984): The Complete Works of Aristotle, The Revised Oxford Translation, vol. 1, Bollingen Series LXXI.2, Princeton, N. J., Princeton University Press.

BARNES, J. (1987): Aristóteles, traducción de Marta Sansigre, Madrid, Cátedra. 
Crombie, A. C. (1974): Historia de la Ciencia: De San Agustin a Galileo. Vol. 1, Siglos V-XIII. Vol. 2, Siglos XIII-XVII, traducción de José Bernia, Madrid, Alianza.

Drake, S. (1986): "Galileo's Pre-Paduan Writings: Years, Sources, Motivations", Studies in History and Philosophy of Science, vol. 17, no 4 (1986), págs. 429-448.

DRAKE, S. (1989): History of Free Fall. Aristotle to Galileo. With an Epilogue on $p$ in the Sky, Toronto, Wall \& Thompson.

DraKe, S. \& Drabkin, I. E. (eds.) (1969): Mechanics in Sixteenth-Century Italy. Selections from Tartaglia, Benedetti, Guido Ubaldo of Galileo, Madison, The University of Wisconsin Press.

GALILEI, G. (1632): Diálogo sobre los dos máximos sistemas del mundo ptolemaico y copernicano, edición, introducción y notas de Antonio Beltrán, Madrid, Alianza, 1994.

GaLILEI, G. (1638): Consideraciones y demostraciones matemáticas sobre dos nuevas ciencias, traducción de Javier Sádaba, introducción y notas de Carlos Solís, Madrid, Editora Nacional, 1981.

GalileI, G. (1890-1909): Le Opere di Galileo Galilei, 20 vols., Edición de Antonio Favaro, Florencia, Tipografia di G. Barbèra. Reimpresiones en 1929 y 1964.

HuTchiNs, R. M. (ed.) (1982) Great Books of the Western World, vol II. Euclid, Archimedes, Apollonius of Perga and Nicomachus, traducciones de Sir Thomas L. Heath (Euclides y Arquímedes); R. Catesby Taliaferro (Apolonio); y Martin L. D'Ooge, Frank E. Robbins y Louis C. Karpinski (Nicómaco), Chicago, The University of Chicago Press. (Orig., 1952.)

KOYRE, A. (1977) Estudios de historia del pensamiento cientifico, traducción de Encarnación Pérez Sedeño y Eduardo Bustos, Madrid, Siglo XXI.

KuHN, T. S. (1962): The Structure of Scientific Revolutions, Chicago \& London, The University of Chicago Press. (3rd. ed., 1996.)

KUHN, T. S. (1978): La revolución copernicana. La astronomía planetaria en el desarrollo del pensamiento occidentah traducción de Domènec Bergadà, Barcelona, Ariel.

KUHN, T. S. (1980) «Los paradigmas cientificos", en B. BARNES (comp.), Estudios sobre sociologia de la ciencia, traducción de Nestor Míguez, Madrid, Alianza, págs. 79-102.

LLoYD, G. E. R. (1996): Adversairs and Authorities. Investigations into Ancient Greek and Chinese Science, Cambridge, Cambridge University Press.

SAMBURSKY, S. (1990): El mundo fisico a finales de la Antigüedad, traducción de Carlos Solis, Madrid, Alianza.

Solts, C. (1983): «La mecánica de Galileo: Un proyecto irrealizado», Historia de la fisica hasta el siglo XIX, Madrid, Real Academia de las Ciencias Exactas, Físicas y Naturales, págs. 71-88. 
L. Vega, L. (ed.) (1986): Arquimedes. El método, traducción de Maria Luisa Puertas y Luis Vega, introducción y notas de Luis Vega, Madrid, Alianza.

Wallace, W. A. (ed.) (1977): Galileo's Early Notebooks: The Physical Questions. A Translation from the Latin, with Historical and Paleographical Commentary, Notre Dame, University of Notre Dame Press.

WallaCe, W. A. (1981): Prelude to Galileo. Essays on Medieval and Sixteenth-Century Sources of Galileo's Thought, Dordrecht, Boston \& London, D. Reidel Publishing Co.

WaLlace, W. A. (1984): Galileo and His Sources. The Heritage of the Collegio Romano in Galileo's Science, Princeton, N. J., Princeton University Press.

WISAN, W. L. (1974): «The New Science of Motion: A Study of Galileo's De motu locali", Archive for History of Exact Sciences, 13 (1974), págs. 103-306. 